\title{
Investigating the effect of carbon tax and carbon quota policy to achieve low carbon logistics operations
}

\author{
Yan Li ${ }^{\mathrm{a}}$, Ming K. Lim ${ }^{\mathrm{a}, *}$, Jiayao Hu${ }^{\mathrm{d}}$, Ming-Lang Tseng ${ }^{\mathrm{b}, \mathrm{c}}$ \\ ${ }^{a}$ College of Mechanical Engineering, Chongqing University, Chongqing 400044, China \\ b Institute of Innovation and Circular Economy, Asia University, Taiwan \\ ${ }^{c}$ Department of Medical Research, China Medical University Hospital, Taiwan \\ ${ }^{\mathrm{d}}$ School of Strategy and Leadership, Coventry University, United Kingdom
}

\begin{abstract}
Developing a low-carbon economy and reducing carbon dioxide emission have become a consensus for both academics and practitioners. However, the existing literature did not pay enough attention in interrogating the impacts of Carbon Tax $(C T)$ and Carbon Quota $(C Q)$ policy on distribution costs and carbon dioxide emission in the field of vehicle routing problem. Moreover, the investigated subsidies factor is also incomplete. This research stands on the position of the company to study the impact of $C T$ and $C Q$ policy on aforementioned two aspects. A mathematical model is developed to achieve the best low carbon vehicle routing under the optimal policy. The optimization goal of this research is to minimize the total cost that includes vehicle-using, transportation, $C T, C Q$, and raw material subsidy costs. An improved optimization algorithm, namely Genetic Algorithm-Tabu Search (GA-TS), is proposed to solve a given business case. In the simulation experiments, GA-TS and a traditional GA are compared and the results show the advantage of GA-TS on reducing the total cost and carbon dioxide emission. Furthermore, the experiments also explore the total cost and carbon dioxide emission under three scenarios (Benchmark, $C T$ and $C Q$ ), incorporating four policies: CT, Carbon Tax Subsidy (CTS), CQ, and Carbon Quota Subsidy (CQS). It is concluded that CQS is the ideal policy to minimize distribution cost and carbon dioxide emission. In addition, the impact of vehicles' capacities on the total cost and carbon dioxide emission is also analyzed in this research. This research also aimed at assisting practitioners in better formulating delivery routes, as well as policy makers in developing carbon policies. Finally, the limitations and the future research directions of this research are also discussed.
\end{abstract}

Keywords: Low carbon logistics, Carbon tax, Carbon quota, Vehicle routing, Genetic algorithm

\section{Introduction}

Global warming, which is mainly caused by greenhouse gas emis-sion, is a major challenge to the sustainable development of human society (Atasoy, 2017). For sustainable development, many countries have set up goals to guide their progress. For example, the Chinese government made a commitment that the carbon dioxide emission per unit of GDP will decline by $40 \%-50 \%$ until 2020 , comparing with 2005 at The 2009 United Nations Climate Conference in Copenhagen (Dai et al., 2011). Carbon dioxide, as the primary greenhouse gas, is widely emitted by the transportation industry (Abedivaraki, 2017). Among the carbon dioxide emission of transportation, $74 \%$ is emitted by the road transportation (Terefe, 2010). Therefore, it is imperative to implement low carbon logistics on the road transportation.

Currently, there is no unified definition of low carbon logistics. Based on the existing literature, this research defined it as the processes of optimizing logistics through the new technology or innovative management methods with the aims of reducing resource consumption and carbon dioxide emission (Lim et al., 2017; He et al., 2017; Ji and Luo, 2017; Tang et al., 2015; Walker and Manson, 2014; Yang et al., 2013) and vehicle routing planning combines new technology and management methods, which could reduce carbon dioxide emission and achieve low carbon logistics (Xiao and Konak, 2017; Xia et al., 2018; Liao, 2017; Ji and Sun, 2017).

In order to alleviate the greenhouse effect, many countries actively formulate policies to reduce carbon dioxide emission (Zhou et al., 2018). For instance, adopting carbon tax $(C T)$ policy and carbon quota $(C Q)$ policy have become effective measures to protect the environment (Tamura and Teraoka, 2011; Zhang et al., 2017a,b; Zhang and Zhang, 2018). CT policy refers to the tax imposed on carbon dioxide emission (Zhang et al., 2017a,b; Wang et al., 2017a). $C Q$ policy allows carbon dioxide to be freely traded in the carbon market as a commodity (Zhao et al., 2018). Jiang et al. (2016) explained that companies need to purchase the carbon dioxide emission right in the carbon market if their carbon emission exceed the government's allocated $C Q$. Companies can also sell carbon emission rights if they have not consumed all of their $C Q$.

Many scholars have taken carbon policies into account to explore the carbon dioxide emission reduction effects in vehicle routing plan-ning (Duan and He, 2014; Li and Zhang, 2014; Zhang et al., 2015; Li et al., 2015; Wang et al., 2017a,b; Chen and Zhu, 2018). The majority of these studies focused on CT. For instance, Duan and $\mathrm{He}$ (2014) devel-oped an open vehicle routing model with soft time windows based on CT and the results showed that the fuel consumption and carbon di-oxide emission can be reduced. Zhang et al. (2015) considered CT policy in their objective function and concluded that the total cost and carbon dioxide emission are both reduced. Wang et al. (2017a,Wang et al., 2017b discussed the impact of different CT on carbon dioxide emission, distribution routes, and distribution cost. There are few stu-dies involving CQ in vehicle routing planning. Li and Zhang (2014) proposed a vehicle routing planning model on the grounds of $C Q$ and proved that it can effectively reduce carbon dioxide emission compared to the traditional path optimization model that merely considers eco-nomic cost. Li et al. (2015) developed an optimization model on the basis of $C Q$ to plan vehicle routing to reduce carbon dioxide emission. Chen and Zhu (2018) constructed a mathematical model to minimize CQ cost by taking vehicle speed, variable load, travel distance, and vehicle type into account. However, there is no comparative study of $C T$ and $C Q$ in the existing vehicle routing planning literature, which makes the ideal policy achieving the achieving the lowest total cost and carbon dioxide emission remain indistinct. But it is very necessary to compare them to find the most ideal policy.

The implementation of $C T$ policy and $C Q$ policy will reduce carbon dioxide emission but the total cost of companies will increase in the meantime (Chen and Xu, 2015; Wang et al., 2017a,b). This brings more financial burdens to companies. Therefore, governments should formulate and adopt Carbon Tax Subsidy (CTS) and Carbon Quota Subsidy (CQS), which add subsidy factors to $C T$ and $C Q$ policy, to effectively promote carbon policies (Galinato and Yoder, 2010). Cao et al. (2017) pointed out that carbon subsidy policies usually include tax breaks and raw material subsidies. Raw material subsidies refer to the subsidies of using clean fuels such as liquefied natural gas (LNG), electricity, hy-drogen and so on. However, the existing literature has not taken the subsidy as a critical factor in to account.

Many scholars have studied the algorithm of vehicle routing plan-ning. Golden et al. (2008) categorized the algorithm into exact algo-rithms and heuristic algorithms. However, applying exact algorithms is difficult to obtain the optimal solution with the increasing amount of data. Hence, heuristic algorithms that 
contain ant colony algorithm, particle swarm optimization, and genetic algorithm to solve the large-scale problem become increasingly popular (Azadeh et al., 2013; Alberdi and Khandelwal, 2015). Goyal and Mittal (2012) clarified that the genetic algorithm is the most effective method compared to the ant colony algorithm, and the particle swarm optimization to solve vehicle routing planning problem. The genetic algorithm is derived from Dar-win's biological evolution law, simulating the natural selection of nat-ural biology and the process of biological evolution (Schubert et al., 2012; Thakur et al., 2017). Zhou et al. (2017) proposed the hybrid multi-population genetic algorithm to study the distribution route of urban logistics in which customers are allowed to extract packages at the intermediate delivery facility. However, genetic algorithms are sometimes trapped in a local optimum during the solving process (Choi et al., 2016; Ge and Wang, 2017). Jiang (2015) stated that the tabu search algorithm could avoid the solution to converge to a local op-timum. Hence, a new algorithm Genetic Algorithm-Tabu Search (GA-TS) is proposed in this research, which combines the features of both tabu search algorithm and genetic algorithm.

In this research, the vehicle routing planning of low carbon logistics model (VRPLC) under $C T$ and $C Q$ policy is developed. Benchmark scenarios, $C T$ scenarios, and $C Q$ scenarios are set up to find the most effective carbon policy by comparing carbon dioxide emission and total cost. The proposed VRPLC model has two main advantages. Firstly, the subsidy policy is added on the basis of carbon policy, which is meeting the national policies. Secondly, the GA-TS algorithm is used to avoid getting stuck in a local optimal solution while solving the case.

This research is organized as follows. This section presents a lit-erature review of low carbon logistics vehicle routing. Section 2 es-tablishes a low carbon logistics vehicle routing model with considera-tion of $C T$ and $C Q$. The GA-TS algorithm and the solving steps are introduced in Section 3. Section 4 describes the experimental and result analysis, which contains algorithm experiment and model experiment. Finally, the conclusions, contributions, limitations and the future work of this research are summarized in Section 5.

\section{Formulation of the optimization model}

\subsection{Calculation of carbon dioxide emission}

The carbon dioxide emission is calculated according to the "Greenhouse gas emission accounting method for land transport en-terprises" (National Development and Reform Commission of People's Republic of China, 2015). As shown in Eq. (1), NVC represents average low calorific value of the LNG, FC represents the LNG consumption, CC represents unit calorific value carbon content of the LNG, and OF re-presents carbon oxidation of the LNG.

$E_{C O 2}=\sum_{N V C \times} F C \times C C \times O F \times \quad \frac{12}{44}$

The LNG consumption is related to the vehicle's load and the dis-tribution distance. The calculation equation is shown in Eq. (2). $X_{0}$ represents the $L N G$ consumption at no load. $X_{1}$ symbolizes the $L N G$ consumption at full load. $Q$ is the maximum capacity of vehicle. $U$ re-presents the goods load of the vehicle. Sij signifies the running distance. Therefore, carbon emission is shown in Eq. (3)

$F C=\sum_{S_{i j}}\left(x_{0}+\frac{X_{1}-X_{0}}{Q} \cdot U\right)$

$E_{C O 2}=\sum_{N V C \times} \sum_{S_{i j}}\left(X_{0}+\frac{X_{1}-X_{0}}{Q} \cdot\right)_{x C C \times O F \times} \frac{12}{44}$

\subsection{Mathematical model}

This research studies the VRPLC model, which can be described as a single distribution center delivers goods to multiple customers. The location coordinates and the demand of each customer are known. Vehicles are in the same type and their speed remains constant during the delivery. They need to be rented when the company's own transport capability is insufficient. All vehicles set off from the distribution center and return to it after finishing the service. Each customer can only be served by one vehicle, whereas each vehicle can serve multiple custo-mers. The distribution process is shown in Fig. 1. The symbols and variables required to build the VRPCL model are in Table 1.

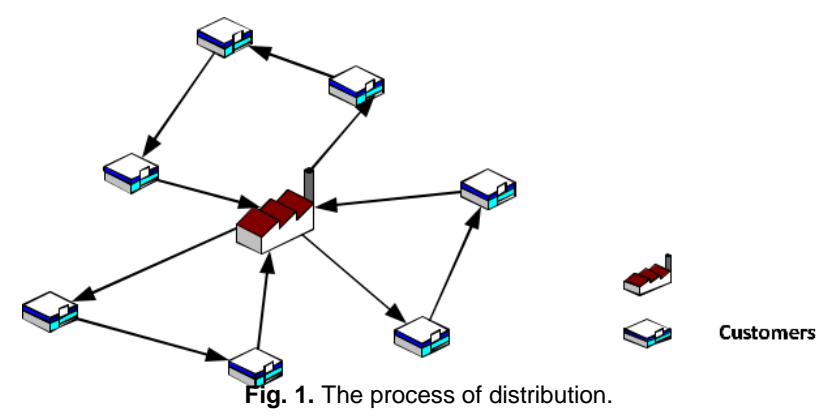

Table 1 Symbols and variables.

\begin{tabular}{ll}
\hline Symbols & Meaning \\
\hline$M$ & Number of customers \\
$W$ & Number of vehicles owned by the distribution center \\
$Z$ & Number of vehicles rented \\
$E_{C O 2}$ & Carbon dioxide emission \\
$F C$ & Consumption of LNG \\
\hline Variables & Meaning \\
\hline$C 1$ & Using cost of distribution center vehicle, unit: RMB/vehicle
\end{tabular}




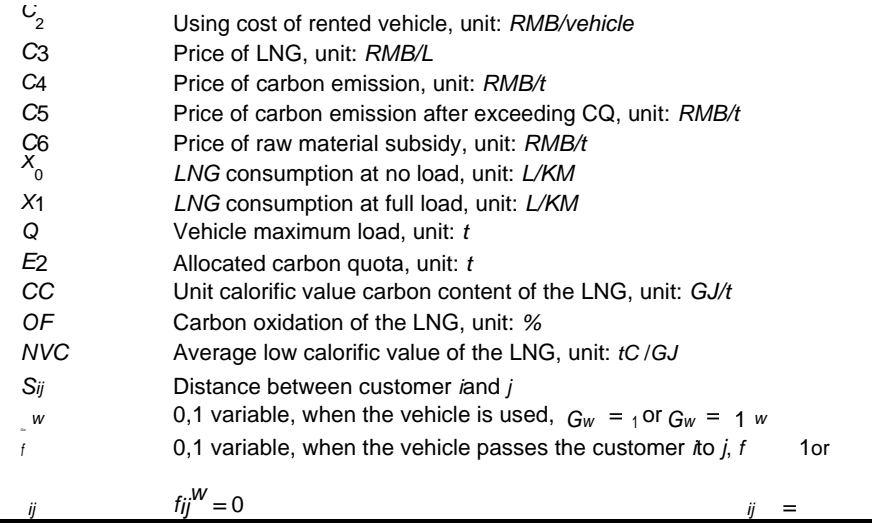

\subsubsection{Cost analysis}

The proposed VRPLC model targets the minimum of total cost, covering vehicle-using cost $\left(T_{1}\right)$, transportation cost $\left(T_{2}\right), \mathrm{CT}$ cost $\left(T_{3}\right), \mathrm{CQ}$ cost (), and raw material subsidy cost (T5).

Vehicle-using cost. The vehicle-using cost is incurred by using the vehicle in the distribution and it consists of the fixed loss cost, the maintenance cost, and the salary of the employee. In this research, the vehicle-using cost is divided into two parts: the owned vehicle cost and the rental cost. The calculation of the vehicle-using cost is shown in Eq. (4).

$\sum_{T_{1}={ }_{w=1}}^{W} \cdot \sum_{C_{1}} \cdot G_{w}+Z C_{2}$

Transportation cost. The transportation cost refers to the $L N G$ consumption cost of the vehicle during transportation. The calculation of the transportation cost is shown in Eq. (5).

$\left.\sum_{T_{2}=C_{3}}^{W} \sum_{w=1}^{M} \sum_{j=0}^{M}\left[f_{j=0}{ }_{i j}^{k} S_{i j} X_{0}+Q \quad \frac{X_{1}-X_{0}}{Q} \cdot U\right)\right]$

Carbon tax cost. Carbon tax cost refers to the cost of carbon dioxide emission under the CT policy, which is related to carbon dioxide emission.

The calculation of the carbon tax cost is shown in Eq. (6).

$T_{3}=C_{4} \sum_{w=1}^{W} \sum_{i=0}^{M} \sum_{j=0}^{M} f_{i j}{ }^{w}\left[N V C \times S_{i j}\left(x_{0}+\frac{X_{-} X_{0}}{Q} \cdot\right)_{\times C C \times O F \times} \frac{12}{44}\right]$

Carbon quota cost. Carbon quota cost refers to the cost of im-plementing the $C Q$ policy, which is directly affected by carbon dioxide emission. The carbon dioxide emission of company is $E_{1}$ and the $C Q$ allocated by the government to the company is $E_{2}$. The Gap stands the difference between the $E_{1}$ and $E_{2}\left(G a p=E_{1}-E_{2}\right)$. Companies can trade carbon dioxide in the carbon market when the Gap is not equal to 0 . If $E_{1}>E_{2}$, the company needs to purchase carbon dioxide emission rights. If $E_{1}<E_{2}$, the company can sell the carbon dioxide emission rights. Therefore, the carbon quota cost is shown in Eqs. (7) and (8).

$T_{4}=C_{5} \cdot\left(E_{1}-E_{2}\right)$
$T_{4}=C_{5} \cdot\left(\sum_{w=1}^{W} \sum_{i=0}^{M} \sum_{j=0}^{M} f_{i j}^{w}\left[I_{N V C \times S_{i j}}\left(X_{0}+\frac{X_{1}-X_{0}}{Q} \cdot U_{\times C C \times O F \times}-\frac{12}{44}-E_{2}\right)\right.\right.$

Raw material subsidy cost. Government often adopts a series of subsidiary measures to help companies to reduce the cost of carbon dioxide emission. The subsidiary measure adopted in this research is the subsidy for using $L N G$ instead of direct subsidies for reduced carbon emissions to promote the use of clean energy. The subsidy cost for raw materials is shown in Eq. (9).

$\sum_{T_{5}=C_{6}}^{w} \sum_{w=1}^{M} \sum_{i=0}^{M}\left[f_{j=0}{ }_{i j}^{w} S_{i j} X_{0}+Q\right.$

\subsubsection{Model establishment}

The VRPLC model is developed under the benchmark scenario, the CT scenario, and the CQ scenario.

Scenario 1. Benchmark scenario.

The vehicle-using cost and the transportation cost are considered in the objective function under the benchmark scenario. The objective function is shown in Eq. (10).

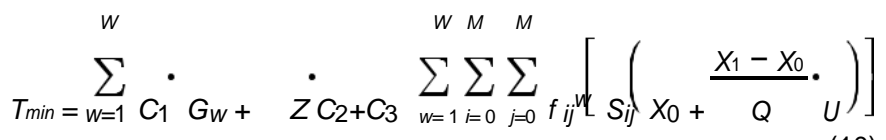

\section{Scenario 2. CT scenario.}

$C T$ scenario contains the $C T$ policy and the CTS policy. CT policy refers to the tax imposed on carbon dioxide emission. When only the $C T$ policy is implemented, the vehicle-using cost, transportation cost and carbon tax cost are taken into account. The objective function is shown in Eq. (11). CTS policy refers to a certain subsidy to companies based on the CT policy. When the CTS policy is implemented, the vehicle-using cost, transportation cost, carbon tax cost, and raw material subsidy cost are all considered. The objective function is presented in Eq. (12). 


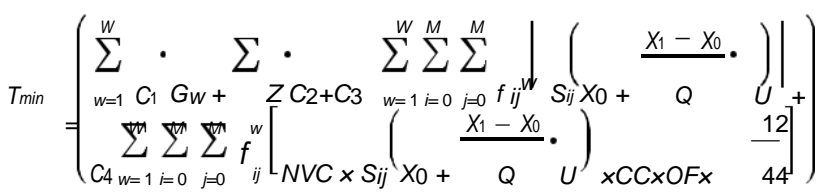

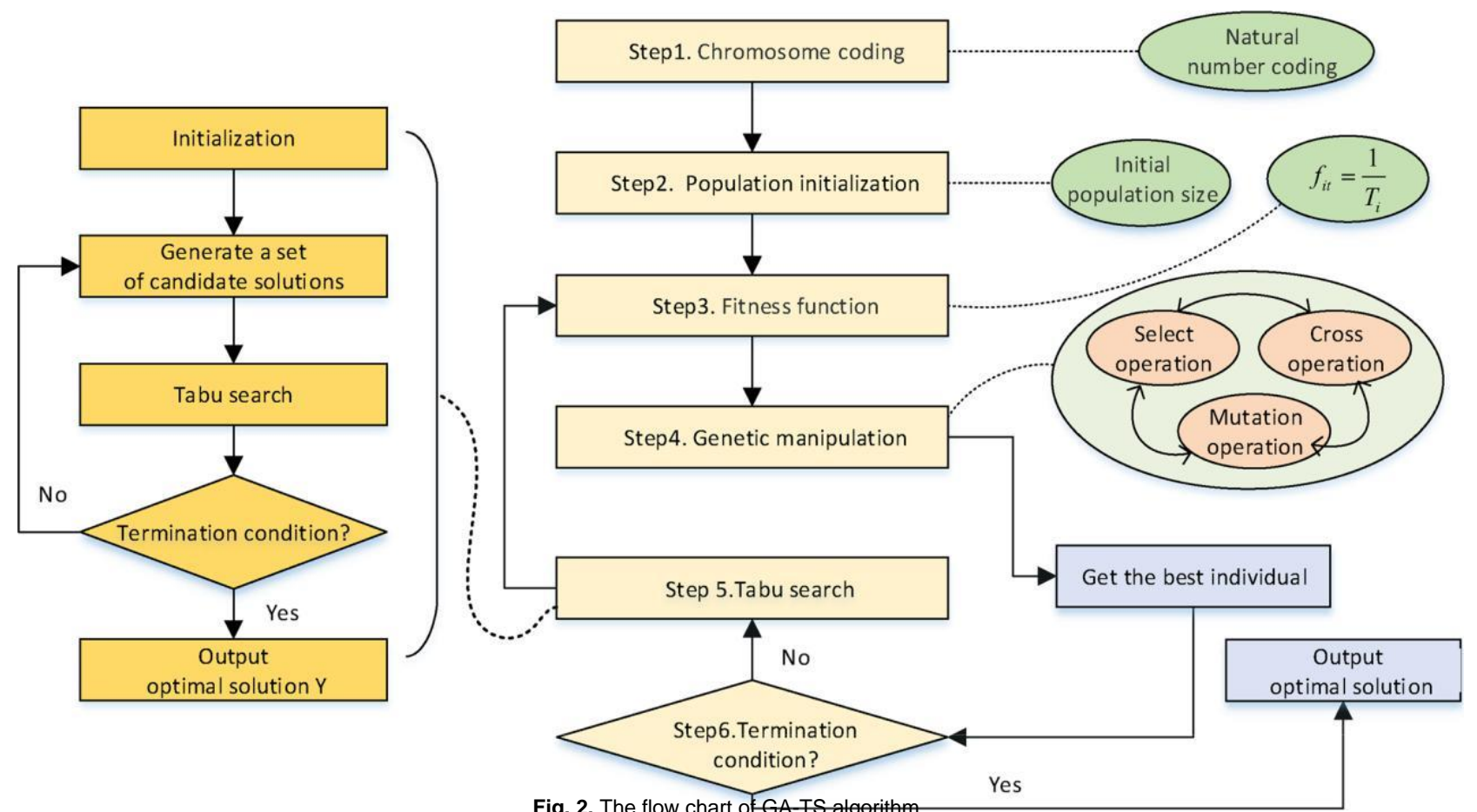

Fig. 2. The flow chart of GA TS algorithm

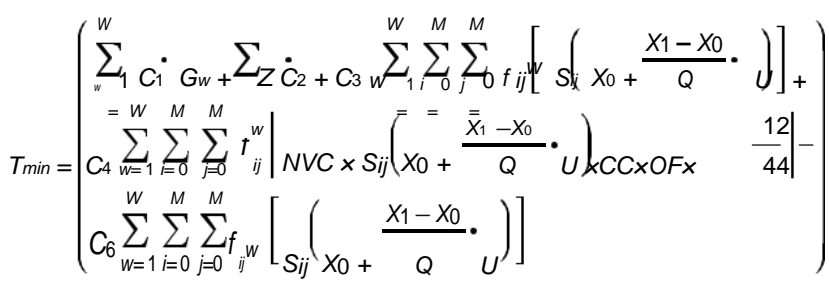

Scenario 3. $C Q$ scenario.

$C Q$ scenario covers $C Q$ policy and $C Q S$ policy. $C Q$ policy refers to the government allocating a certain carbon emission right to companies and the companies need to pay the carbon cost when exceeding the allocated carbon emission. When the $C Q$ policy is applied, the objective function, which considers the vehicle-using cost, transportation cost, and carbon quota cost, is shown in Eq. (13). CQS policy refers to the government providing a certain subsidies based on the $C Q$ policy. When the CQS policy is implemented, the raw material subsidy cost should also be considered. The objective function is presented in Eq. (14).

Constraints.

$\sum_{j=1}^{M} \sum_{w=1}^{W} \geq \underset{f_{i j}{ }^{W}}{Z}, i=0$

$\sum_{i=1}^{M} \leq f_{i j} q_{i j} Q, w=1,2,3 \ldots, W$

$\sum_{J=1}^{M} f_{i j}=\sum_{J=1}^{M} \leq f_{j i}{ }^{W} \quad 1, w=1,2,3 \ldots, W$

Eq. (15) represents that the number of routes is more than or equal to the vehicles owned by the distribution center. Eq. (16) represents that the load capacity of the vehicle cannot exceed its maximum load. qi represents the cargo weight of the customer. Eq. (17) represents that the vehicle must return to the distribution center after finishing the service. 


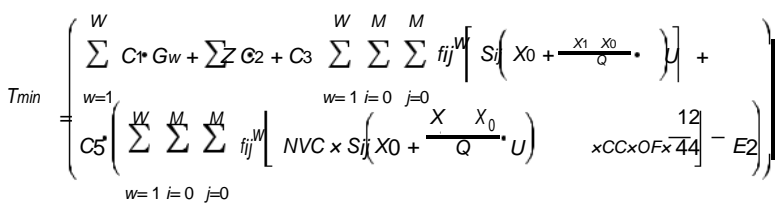

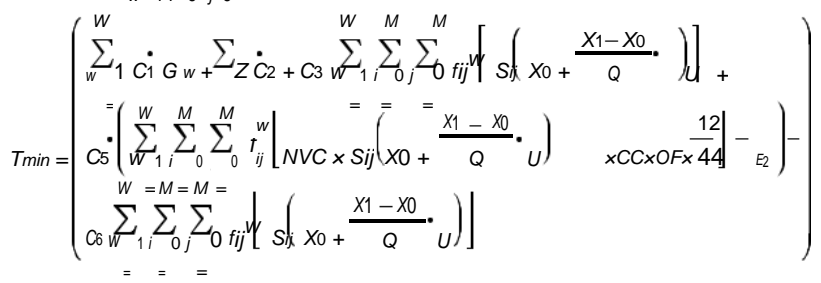

The GA-TS is proposed to solve the VRPLC model in this research, which contains six steps (shown in Fig. 2).

Step1. Chromosome coding. It is necessary to convert the feasible

\begin{abstract}
scheme into a chromosome set before the genetic algorithm search, and then the calculations of moderate functions and genetic manipulations can be performed. The coding method used in this research is natural number coding, and the order of customers is in one-to-one correspondence with the order of vehicles. For example, a randomly gener-ated customer sequence is 245,361 , and the sequence of a group of vehicles obtained under the constraint condition is 112,233 . The two sets of digital sequences can be understood as: the first vehicle delivers to customers 2 and 4 , the second vehicle delivers to customers 5 and 3 ,
\end{abstract}

and the third vehicle delivers to customers 6 and 1.

Step 2. Population initialization. The genetic algorithm starts from the population of the problem solution, so an initial population composed of individuals is generated as the starting point of the evo-lution. The size of the initial population affects the effectiveness of the algorithm. If the population size is too small, the search space will be limited; if the population size is too large, the search efficiency will be reduced.

Step 3. Fitness function. The fitness function is used to evaluate an individual's ability to adapt to the environment. In general, the fitness function is transformed from the objective function. The objective function of this research aims to minimize the total cost. For the com-panies, the lower the total cost, the better the performance. Therefore, there is a negative correlation between the total cost and the fitness function. The reciprocal of the total cost is taken as the fitness function $\left(f_{i t}\right)$ and it is shown as $f_{i t}=1 / T_{\text {min }}$.

Step 4. Genetic manipulation. Genetic manipulation is the key to genetic algorithms. The individual is constantly improved by adapting the individual's genetic operations to change its fitness. The genetic manipulation includes the selection operation, the cross operation, and the mutation operation, which are explained in the following.

The purpose of the selection operation is to increase the probability that a good individual in the current population will inherit to the next generation. The roulette selection method is used in this research. By comparing the fitness function value of each chromosome with all fit-ness values of the current population, the ratio is used to determine the probability that each chromosome is selected, thereby making the se-lection. The probability that an individual is selected is inversely pro-portional to its fitness value. The greater the individual's fitness value, the greater the probability of being selected to breed to the next gen-eration.

After selecting individuals with good performance in the popula-tion, one or more parts of the two individuals are exchanged by the crossover operator. This research adopts the cyclic cross method. Fig. 3 shows the process of applying this method. For example, the customer sequence of the parent individual 1 is $24,538,671$, the sequence of the parent individual 2 is $51,786,342$, and the sequence of the loop be-tween the two parents is 257,412 . Firstly, copy the loop part of parent 1 to the descendant. Secondly, the position of parent 2 that has been occupied by parent 1 is deleted, and the rest is passed to the descen-dant. Hence, the sequence of the descendant is $24,586,371$.

The mutation operation refers to the replacement of genes in one or more regions of a chromosome by other genes in order to make the chromosome more diverse. This paper uses a transform mutation op-eration, which exchanges any two genes of an individual. For example, the sequence of the original chromosome is 24,538,671. Now, gene 5 and gene 6 are exchanged, and the chromosomal sequence after mu-tation is $24,638,571$. The process is shown in Fig. 4.

Step 5. Tabu search. The operation process of the tabu search al-gorithm: First, an initial solution $X$ is generated, a set of neighborhood solutions is generated according to the initial solution, and the best feasible solution $Y$ is selected, and the iteration is repeated until a certain termination criterion is met. The process is as follows:

(1) Initialization: The initial solution $X$ is generated, and the optimal solution $X^{\prime}=X$ is set, and the taboo table is empty.

(2) Generate a set of candidate solutions: generating a number of neighborhood solutions using the domain function of the current solution. 
(3) Tabu search: find the optimal solution $Y$ from the neighborhood solution set. If the contempt criterion is satisfied, $Y$ replaces $X$ to become the new current solution, and replaces the taboo object that

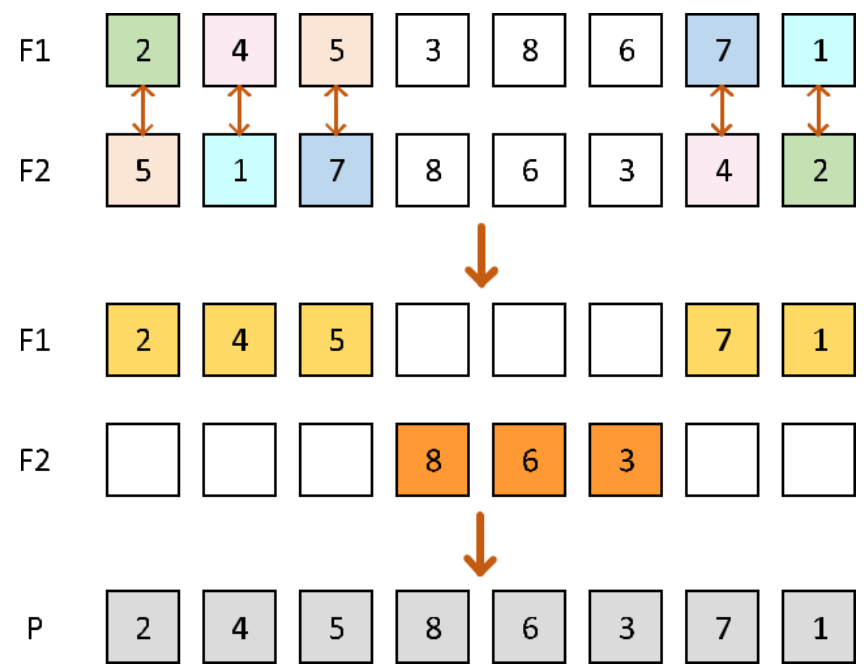

Fig. 3. Cyclic crossover operation process.

entered the taboo table by the new taboo object corresponding to $Y$. If not, the initial solution is removed from the domain solution and returned to step (1).

(4) Modify the taboo table: If the termination condition is met, the optimal solution $Y$ is output, otherwise go to step (2).

Step 6. Terminating operation: The evolution is stopped when the number of entire process loops is greater than the upper limit of the set number of iterations. In the last generation of the population, the dis-tribution route corresponding to the individual with the best fitness value is the optimal delivery route.

\section{Experimental design and result analysis}

The experimental design is divided into two sections. GA and GA-TS are compared in Section 4.1 through the standard test cases. In Section 4.2 , the proposed model is analyzed from different aspects by a prac-tical distribution problem in a company. Model parameters are set as shown in Table 2.

\subsection{Algorithm experiment}

This section takes the benchmark scenario (i.e. Eq. (10)) as an ex-ample for algorithm experiment. The empirical data is based on the work by Desaulniers et al. (2016), which consists of a database of six sets of customer information (i.e. C1, R1, RC1, C2, R2, and RC2) as the well-known study data. This research selects one problem randomly in each set, and forms a test case collection (C1-04, C2-06, R1-07, R2-03, RC1-05, RC2-07). Each problem is solved by GA and GA-TS respec-tively. The best solutions are then obtained (shown in Table 3). The parameters of the proposed algorithm are as follow: the maximum

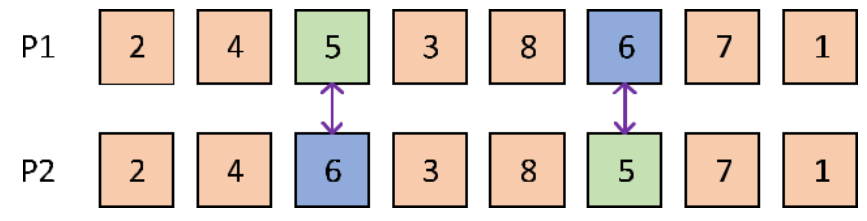

Fig. 4. Transform mutation operation process. 
Table 2 Model parameters.

\begin{tabular}{llll}
\hline Parameters & Meaning & Unit & Value \\
\hline$W$ & Vehicles owned by DC & Vehicle & 3 \\
$v$ & Vehicle speed & $\mathrm{km} / \mathrm{h}$ & 30 \\
$C 1$ & DC vehicle cost & $\mathrm{RMB} /$ & 150 \\
& vehicle & \\
$C 2$ & Rented vehicle cost & $\mathrm{RMB} /$ & 250 \\
& vehicle & \\
$C 3$ & LNG price & $\mathrm{RMB} / \mathrm{L}$ & 3.73 \\
$C 4$ & Carbon price of carbon tax & $\mathrm{RMB} / \mathrm{t}$ & Variable \\
$C 5$ & Carbon price when carbon quota is & $\mathrm{RMB} / \mathrm{t}$ & Variable \\
$C_{6}$ & exceeded & $\mathrm{RMB} / \mathrm{t}$ & Variable \\
$E_{2}$ & Subsidy price & $\mathrm{t}$ & Variable \\
$Q$ & Allocated carbon quota & $\mathrm{t}$ & 3 \\
$X_{0}$ & Vehicle maximum load & $\mathrm{L} / \mathrm{km}$ & 0.125 \\
$X 1$ & Fuel consumption at no load & $\mathrm{L} / \mathrm{km}$ & 0.326 \\
$C C$ & Fuel consumption at full load & $\mathrm{tC} / \mathrm{GJ}$ & 0.0153 \\
& Unit calorific value carbon content of & & \\
OF & LNG & None & 0.99 \\
$N V C$ & Average low calorific value of LNG & $\mathrm{GJ} / \mathrm{t}$ & 43.33 \\
\hline
\end{tabular}

number of iterations is 500 ; the number of population is 100 ; the cross probability is 0.54 ; the mutation probability is 0.05 . From Table 3 , the results of GA-TS are better than that of GA in terms of travelling dis-tance and total cost, which verify that GA-TS performs better than GA.

\subsection{Model experiment}

The purpose of the model experiment is to validate the VRPLC model. This paper sets up an in-house case, assuming that XY logistics predominantly provides distribution services, who has one distribution center (DC) and twenty customers need be serviced. The customer information including coordinates and demands is shown in Table 4. The coordinates of the DC are (36, -22.75). The GA-TS is used to solve the proposed case.

\subsubsection{Analysis in different scenarios}

This section explores total cost and carbon emission in different scenarios (Benchmark scenario, $C T$ scenario and $C Q$ scenario). The re-sult of the total cost and carbon emission in the benchmark scenarios is shown in Table 5. Furthermore, the values of $C_{4}$ and $C_{6}$ in the $C T$ sce-nario, the values of $E_{2}$ and $C_{5}$ in the $C Q$ scenario are determined in the next paragraph.

Assume that carbon prices of carbon tax $\left(C_{4}\right)$ are set as $0.5,1,1.5,2,2.5,3 \mathrm{RMB} / \mathrm{kg}$ (Wang et al., 2017a,b). In order to reduce the impact of the carbon dioxide emission cost on the total cost, the subsidy price $\left(C_{6}\right)$ is set to increase as $C_{4}$ rises. Hence, $C_{6}$ are set as $90,180,270,360,450,540$ RMB/t. The carbon quota $(E 2)$ is set according to the actual carbon

Table 3 The results under GA and GA-TS.

\begin{tabular}{|c|c|c|c|c|c|c|c|}
\hline \multirow[t]{2}{*}{ Set } & \multirow[t]{2}{*}{ Problem } & \multicolumn{3}{|l|}{$\mathrm{GA}$} & \multicolumn{3}{|l|}{ GA-TS } \\
\hline & & Vehicles & Distance $(\mathrm{km})$ & Cost (RMB) & Vehicles & Distance (km) & Cost (RMB) \\
\hline $\mathrm{C} 2$ & 06 & 6 & 900.33 & 1725.39 & 5 & 744.66 & 1518.14 \\
\hline $\mathrm{R} 1$ & 07 & 6 & 822.88 & 1692.63 & 5 & 680.58 & 1411.98 \\
\hline $\mathrm{R} 2$ & 03 & 6 & 775.81 & 1694.96 & 5 & 697.89 & 1431.22 \\
\hline $\mathrm{RC} 1$ & 05 & 6 & 1131.66 & 1955.95 & 6 & 967.93 & 1823.19 \\
\hline $\mathrm{RC} 2$ & 07 & 6 & 998.56 & 1941.69 & 6 & 877.51 & 1788.53 \\
\hline
\end{tabular}

emission of company. The EU plans to reduce carbon dioxide emission by more than $30 \%$ by 2030 (Yonhap News Agency, 2018). Therefore, this paper sets the allocated carbon quota is $70 \%$ of carbon emission in the benchmark scenario. In order to better study the impact of different allocated carbon quota $\left(E_{2}\right)$ on total cost and carbon emission. The $E_{2}$ are set as 29, 28, 27, 26, 25, $24 \mathrm{~kg}$. As carbon quota is reduced, carbon dioxide emission right becomes scarce. Hence, the carbon price of carbon quota exceeded (C5) gradually increase. $C_{5}$ is set as $3,4,5,6,7,8$ $\mathrm{RMB} / \mathrm{kg}$. Table 6 shows the detailed setting. The simulation results of three scenarios are shown in Table 6 and the vehicle routes are shown in Appendix A. The results are analyzed from two perspectives: total cost and carbon emissions.

Total cost. Based on Table 7, the total cost varies with the carbon price. Fig. 5 presents the total cost comparison among B, CT, CTS, CQ and $C Q S$ policy as carbon price rises. As carbon price $\left(C_{4}\right.$ or $\left.C_{5}\right)$ in-creases, the total cost continues to increase regardless of implementing the $C T$ or $C Q$ policy, which are still higher than the total cost $1554.84 \mathrm{RMB}$ in the benchmark scenario. The total cost increased under the $C T$ policy scenario is more than that of the $C Q$ policy scenario. It concluded that implementing carbon policy increases the total cost of the company and the cost pressure of CT policy is more serious. Moreover, comparing to the results of the benchmark scenario, adopting the CTS policy or CQS policy could reduce the total cost. The total cost of implementing the CQS policy is lower than that of the CTS policy. It concluded that implementing CTS policy or CQS policy can reduce total cost of the company and the cost reduction effect brought by CQS policy is more obvious.

This paragraph explains the reason why the total cost continues to increase as the carbon prices ( $C_{4}$ or $\left.C_{5}\right)$ rise when the $C T$ policy or $C Q$ policy is implemented. The rise of carbon cost ( $T_{3}$ and $\left.T_{4}\right)$ is due to the increasing carbon price according to Eqs. (6) and (8). In order to alle-viate the increase in carbon cost, the VRPLC model will optimize the deliver distance to reduce the carbon emission based on Eq. (3). Therefore, the transportation cost is reduced based on Eq. (5). As the higher degree of increase in carbon tax cost while the amount of re-duction of transportation cost is lower, the total cost will continue to increase.

Through comparing the five policies of $B, C T, C T S, C Q$, and $C Q S$, this paper argued that implementing carbon policies (CT policy and $C Q$ policy) will merely reduce carbon dioxide emission, which plays a significant role in environmental protection. However, this will increase the total cost. Therefore, carbon subsidy policies should be im-plemented (forming CTS policy and CQS policy) in order to reduce the cost pressure of 
companies, and CQS has the best cost performance. To conclude, from the perspective of total cost, the order of the four po-licies from superior to poor is: CQS policy, CTS policy, CQ policy and CT policy.

Carbon emission. Different carbon prices lead to changes in carbon dioxide emission. Fig. 6 is extracted from Table 7 to observe the carbon

Table 4 Customer information.

\begin{tabular}{|c|c|c|c|c|c|c|c|c|c|c|}
\hline Number & 1 & 2 & 3 & 4 & 5 & 6 & 7 & 8 & 9 & 10 \\
\hline$x$ & -66.17 & 2.67 & -57.75 & 80.97 & 8.41 & 4.57 & -34.19 & 15.87 & -76.42 & -53.62 \\
\hline$Y$ & -60.81 & -35.22 & 26.62 & -6.11 & -81.27 & 26.06 & -76.70 & 8.72 & 19.28 & 3.79 \\
\hline Demand & 0.65 & 0.80 & 0.05 & 1.00 & 0.25 & 0.50 & 0.50 & 0.10 & 0.25 & 1.20 \\
\hline Number & 11 & 12 & 13 & 14 & 15 & 16 & 17 & 18 & 19 & 20 \\
\hline$x$ & 53.49 & -22.61 & 19.61 & -51.25 & 76.34 & -23.60 & 87.44 & 19.12 & -42.25 & 68.03 \\
\hline Y & -3.31 & -12.79 & -39.55 & -13.76 & -45.94 & -63.11 & -31.38 & 69.04 & 52.43 & -12.48 \\
\hline Demand & 0.35 & 0.95 & 0.75 & 0.80 & 0.55 & 0.20 & 0.80 & 0.65 & 0.60 & 0.70 \\
\hline
\end{tabular}

Table 5 Simulation results under benchmark scenario.

\begin{tabular}{lll}
\hline Scenarios & $T$ & $E_{\text {cO2 }}$ \\
\hline Benchmark & 1554.84 & 41.00 \\
\hline
\end{tabular}

Table 6 Variable values.

\begin{tabular}{lllll}
\hline Standard & $C_{4}$ & $C 6$ & $E_{2}$ & $C 5$ \\
\hline 3 & 1.5 & 270 & 27 & 5 \\
4 & 2.0 & 360 & 26 & 6 \\
5 & 2.5 & 450 & 25 & 7 \\
6 & 3.0 & 540 & 24 & 8 \\
\hline
\end{tabular}

Table 7Simulation results under three scenarios.

\begin{tabular}{|c|c|c|c|c|c|c|c|c|}
\hline Scenario & Policy & Standard & C4 & C5 & $E_{2}$ & C6 & $T$ & $E_{\mathrm{CO} 2}$ \\
\hline Benchmark & $B$ & - & - & - & - & - & 1554.84 & 41.00 \\
\hline \multirow[t]{12}{*}{ CT } & CT & 1 & 0.5 & - & - & - & 1556.12 & 40.10 \\
\hline & & 2 & 1 & - & - & - & 1565.03 & 39.59 \\
\hline & & 3 & 1.5 & - & - & - & 1567.39 & 38.81 \\
\hline & & 4 & 2 & - & - & - & 1573.54 & 38.23 \\
\hline & & 5 & 2.5 & - & - & - & 1581.69 & 37.76 \\
\hline & & 6 & 3 & - & - & - & 1593.4 & 37.46 \\
\hline & CTS & 1 & 0.5 & - & - & 90 & 1516.4 & 38.71 \\
\hline & & 2 & 1 & - & - & 180 & 1517.03 & 38.30 \\
\hline & & 3 & 1.5 & - & - & 270 & 1517.56 & 37.90 \\
\hline & & 4 & 2 & - & - & 360 & 1521.88 & 37.68 \\
\hline & & 5 & 2.5 & - & - & 450 & 1517.06 & 37.05 \\
\hline & & 6 & 3 & - & - & 540 & 1519.73 & 36.77 \\
\hline \multirow[t]{12}{*}{$\mathrm{CQ}$} & $C Q$ & 1 & - & 3 & 29 & - & 1555.35 & 39.60 \\
\hline & & 2 & - & 4 & 28 & - & 1553.88 & 38.70 \\
\hline & & 3 & - & 5 & 27 & - & 1560.48 & 38.40 \\
\hline & & 4 & - & 6 & 26 & - & 1566.69 & 37.91 \\
\hline & & 5 & - & 7 & 25 & - & 1576.51 & 37.46 \\
\hline & & 6 & - & 8 & 24 & - & 1583.51 & 36.90 \\
\hline & CQS & 1 & - & 3 & 29 & 90 & 1483.28 & 37.08 \\
\hline & & 2 & - & 4 & 28 & 180 & 1483.32 & 36.81 \\
\hline & & 3 & - & 5 & 27 & 270 & 1481.61 & 36.56 \\
\hline & & 4 & - & 6 & 26 & 360 & 1481.14 & 36.31 \\
\hline & & 5 & - & 7 & 25 & 450 & 1482.13 & 35.83 \\
\hline & & 6 & - & 8 & 24 & 540 & 1482.72 & 35.42 \\
\hline
\end{tabular}

dioxide emission change more intuitively. It shows the relationship between carbon dioxide emission and carbon price. As carbon price ( $C_{4}$ or $C_{5}$ ) increases, the carbon dioxide emission continues to decline under CT, CQ, CTS, and CQS policy. Comparing to the carbon dioxide emission under $C T$ policy and $C Q$ policy, they both lower than $41 \mathrm{~kg}$ in the benchmark scenario and carbon dioxide emission under $C Q$ policy is lower than CT policy. When CTS policy and CQS policy are adopted, the reduction in carbon dioxide emission is more pronounced. They both lower than the carbon dioxide emission under benchmark scenario and the carbon dioxide emission of implementing the CQS policy is lower than that of the CTS policy. 


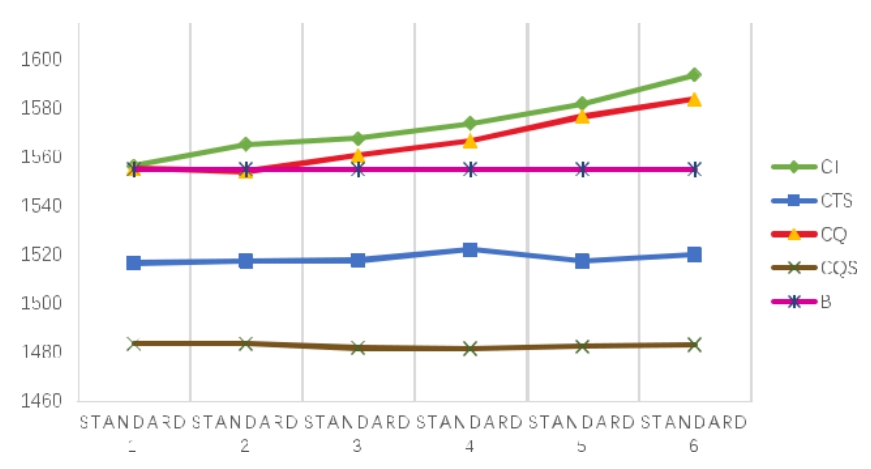

Fig. 5. Total cost change under $B, C T, C T S, C Q$ and $C Q S$ policy, Unit: $R M B$.

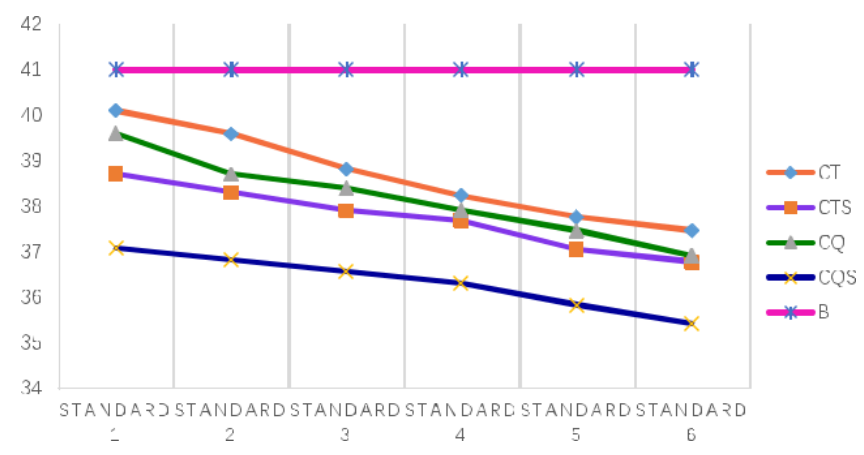

Fig. 6. Carbon emission under $B, C T, C T S, C Q$ and $C Q S$ policy, Unit: $k g$.

This paragraph explains the reason why the higher carbon prices $\left(C_{4}\right.$ or $\left.C_{5}\right)$, the lower the carbon dioxide emission. As the carbon prices rise, the carbon cost $\left(T_{3}\right.$ or $\left.T_{4}\right)$ is increased based on Eqs. (6) and (8). When the carbon cost rises, the VRPLC model will search for the deliver route with lower carbon dioxide emission to reduce the total cost. Therefore, as the carbon prices continue to rise, carbon dioxide emission is gra-dually decreasing. At the same time, according to the Eq. (3), it can be known that the VRPLC model reduces carbon dioxide emission through optimizing deliver distance.

Through comparing the five policies of $B, C T, C T S, C Q$, and $C Q S$, the

Table 8 Results of different vehicle capacity.

\begin{tabular}{lllll}
\hline Capacity & Vehicles & Routes & Total cost (RMB) \\
\hline 3 & 4 & $0-11-20-4-17-0,0-12-19-18-6-0,0-8-14-10-3-9-1,0-13-2-16-7-5-15$ & 1481.62 & Eco2 (kg) \\
4 & 4 & $0-8-6-18-19-10-12-0,0-3-9-14-1-7-16-2-0$ 0-11-20-4-17-15-0,0-13-5-0, & 1456.39 & 36.56 \\
5 & 3 & $0-13-2-12-14-1-7-16-5-0,0-11-20-4-17-15-0,0-8-6-18-19-3-9-10-0$ & 1120.56 & 30.03 \\
\hline
\end{tabular}

carbon dioxide emission under carbon policies (CT policy and $C Q$ policy) are lower than the benchmark scenario and the carbon subsidy policies (CTS policy and CQS policy) can reduce the carbon emission more effectively as compared to the carbon policies (as shown in Fig. 6). Therefore, from the perspective of carbon dioxide emission, the order of the four policies from superior to poor is: CQS policy, CTS policy, CQ policy and CT policy.

Based on above analysis, considering the total cost and carbon di-oxide emission, the following conclusions could be drawn. Implementing carbon policies ( $C T$ policy or CQ policy) can reduce carbon dioxide emission, but the total cost will be increased. So carbon subsidy policies (CTS policy or CQS policy) should be adopted, that not only reduce carbon dioxide emission but also cut the total cost. Taking into account the total cost and carbon dioxide emission, four policies are ranked from excellent to bad is: 1) CQS policy, 2) CTS policy, 3) CQ policy and 4) CT policy.

\subsubsection{Analysis in different vehicle capacity}

This section explores the impact of different vehicle capacities on total cost and carbon dioxide emission under the CQS policy. The ca-pacities of vehicle are set $3 \mathrm{t}, 4 \mathrm{t}$, and $5 \mathrm{t}$ respectively, carbon quota $\left(E_{2}\right)$ is $27 \mathrm{~kg}$, raw material subsidy $\left(C_{6}\right)$ is 270 yuan/t, the carbon price when the carbon quota exceeded $\left(C_{5}\right)$ is 5 yuan $/ \mathrm{kg}$. The optimal solution is obtained to form the Table 8 and the vehicle routing is shown in Ap-pendix B.

According to Table 7, both the total cost and carbon dioxide emis-sion decrease as the vehicle capacity increases. This is because both the total cost and carbon dioxide emission are related to LNG consumption (see Eqs. (5) and (8)), which is related to the travelling distance and the real-time load (Eq. (2)). Based on Table 7, the process of optimization can be explained in two aspects: 1 ) when using the vehicle capacity $Q=3$ or $Q=4$, the number of vehicles is 4 , this process reduces $L N G$ consumption through the adjustment of the deliver order (affect Real-time load). In the second stage, when $Q=5$, the number of vehicles is 3 , the reduction in the number of vehicles leads less invalid traveling distance, so the process mainly reduces by shorting the travelling dis-tance. Based on above analysis.

For this case, it can be drawn that using large capacity vehicle is conducive to reduce total cost and carbon dioxide emission. However, when the number of customers is fixed, the less vehicles used, the more customers serviced by per vehicle, so it is difficult to guarantee the deliver time when the customer has strict requirements on time. Based on above analysis, the company should combine the specific situation to develop a distribution plan. 


\section{Conclusions}

This research develops a low carbon logistics vehicle routing planning model on the grounds of the carbon policy with the goal of minimizing the total cost including the vehicle-using, transportation, carbon tax, carbon quota, and raw material subsidy costs. The GA-TS algorithm is proposed to solve the model by using the data from a practical business case, and the effectiveness of the model is verified by algorithm experiments and model experiments.

This research finds the following conclusions. First, the GA-TS al-gorithm is proved to be effective comparing to GA. Second, the simu-lation results show that the carbon dioxide emission is reduced when the carbon policy ( $C T, C Q, C T S$ or $C Q$ ) adopted, but the implement of $C T$ and $C Q$ increases the total cost. Combining the total cost and carbon dioxide emission, four policies are ranked from good to bad is: 1) CQS policy, 2) CTS policy, 3) $C Q$ policy and 4) $C T$ policy. Third, this research concludes that carbon dioxide emission and total cost are decreased as the vehicle capacity increases.

This research has theoretical and practical contributions. In theory, this study expands the carbon policy research in the field of vehicle routes optimization. CT policy and CQ policy are compared and sub-sidiary factor is considered to form CTS and CQS policies. Moreover, the improved GA-TS is proposed and identified that CQS policy is ideal for cost and carbon dioxide emission reduction. In practice, for company, this research provides an effective model to plan the delivery routes that achieves the balance between the economy and environment. Two advices on developing carbon policy for government are offered. One is that subsidies should be given to companies by subsidizing low-carbon raw materials, which are conducive to reduce carbon dioxide emission and the total cost. The other is that the carbon quota obtained free of charge should be reduced, which will increase the cost pressure on companies, promote companies to carry out technological upgrading and innovation in management methods, achieving a win-win situation between the economy and the environment.

There are also some limitations in the proposed VRPCL model. The calculation method of the fuel consumption does not consider the traffic congestion. Hence, a new fuel consumption model could be adopted in the future research. Moreover, the vehicle routing planning for multiple distribution centers is a future research direction with the number of customers increasing.

\section{Conflict of interests}

We confirmed that there is no conflict of interests in relation to this manuscript.

\section{Acknowledgement}

This research is funded by the Chongqing Science and Technology Commission (Project no. cstc2019jscx-msxmX0189). 
See Figs. A1-A4.

(a)

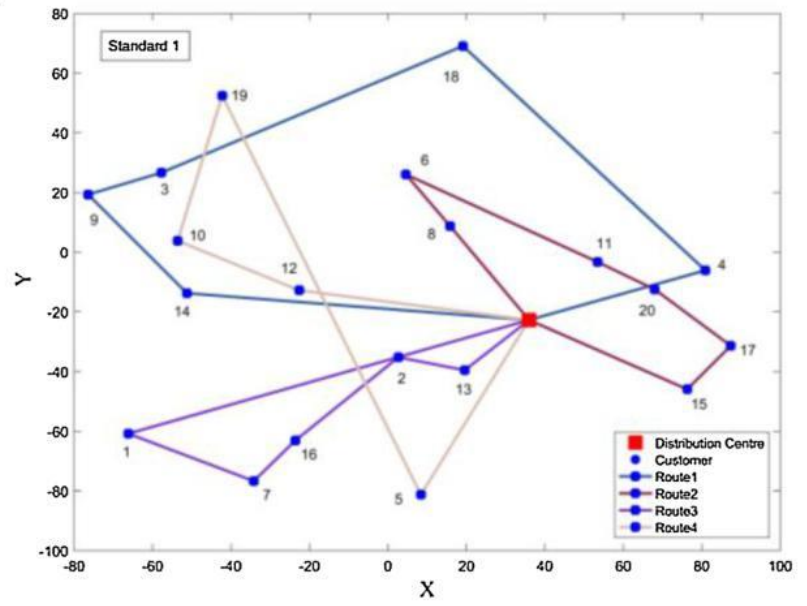

(c)

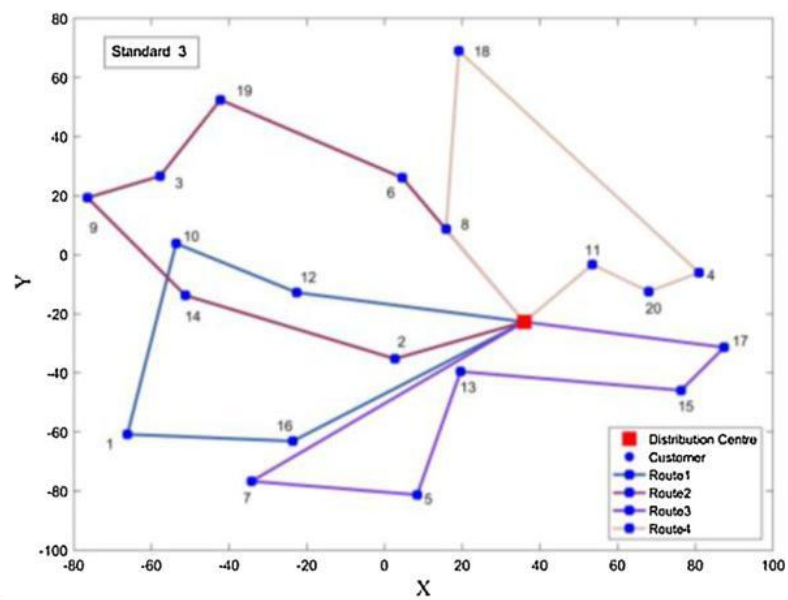

(e)

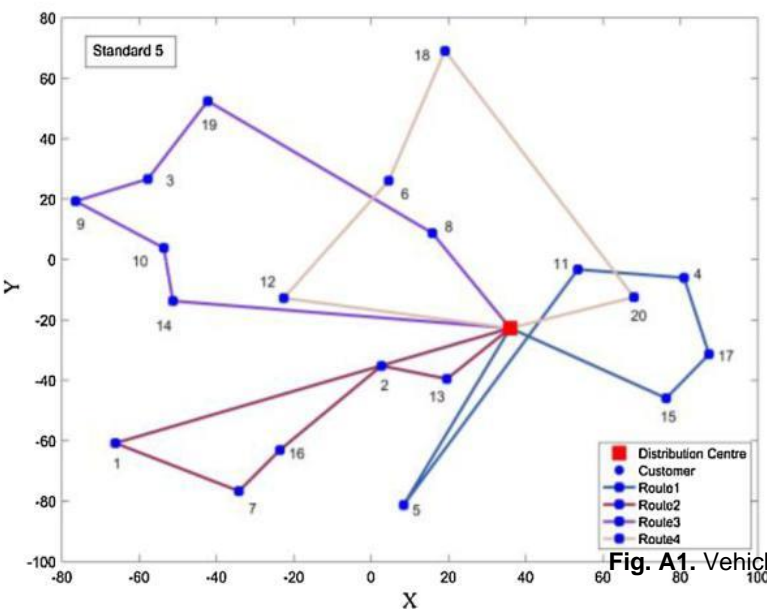

(b)

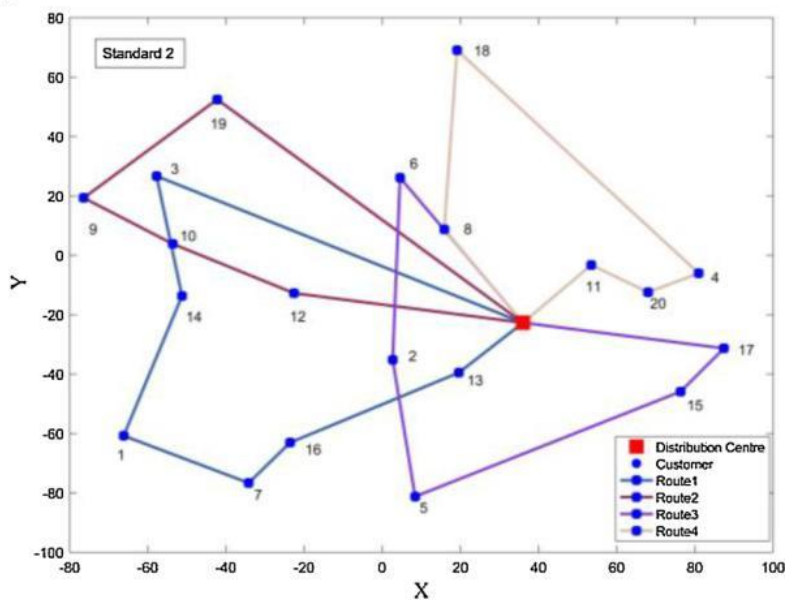

(d)

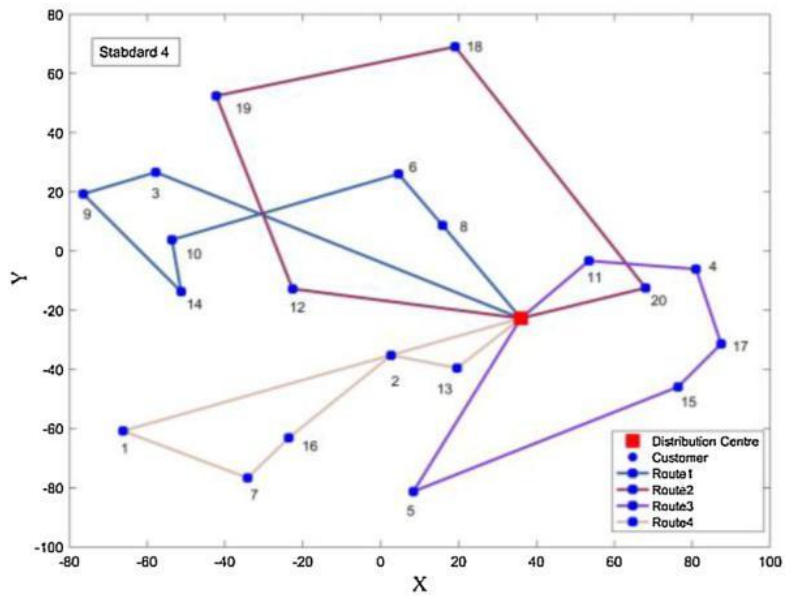

(f)

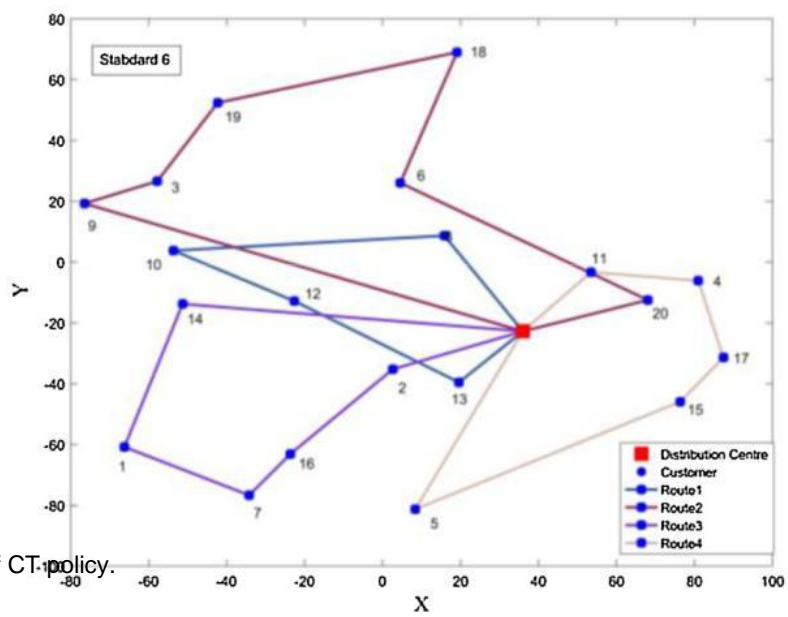


(a)

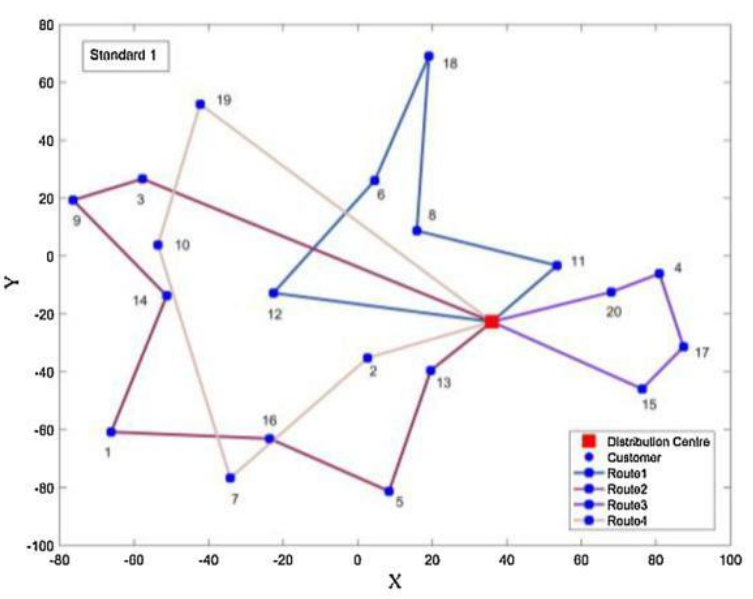

(c)

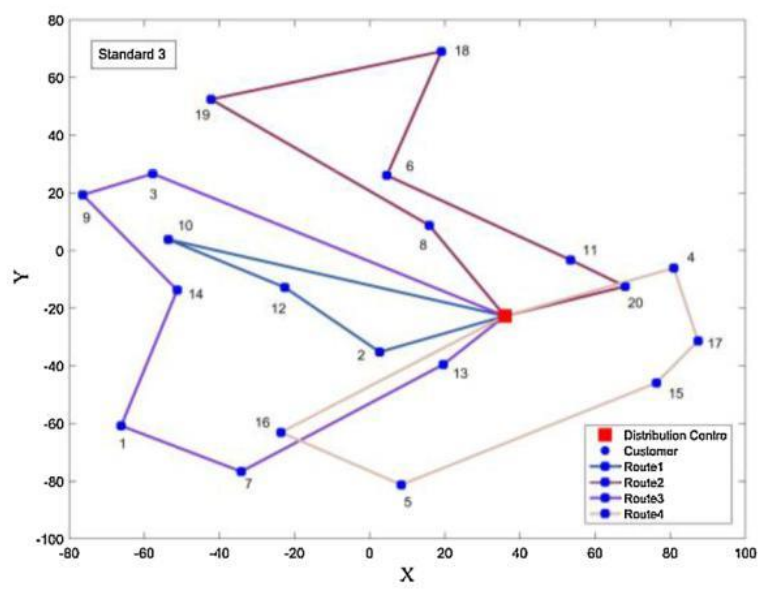

(e)

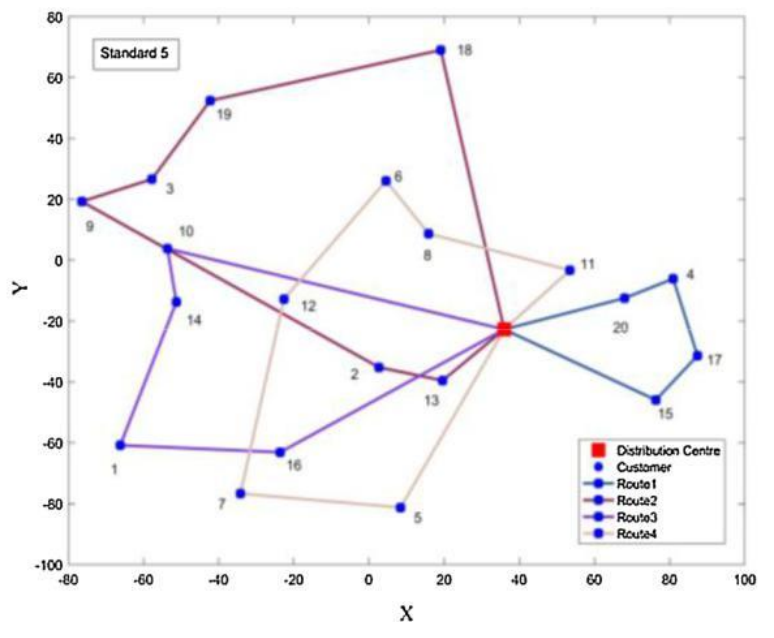

(b)

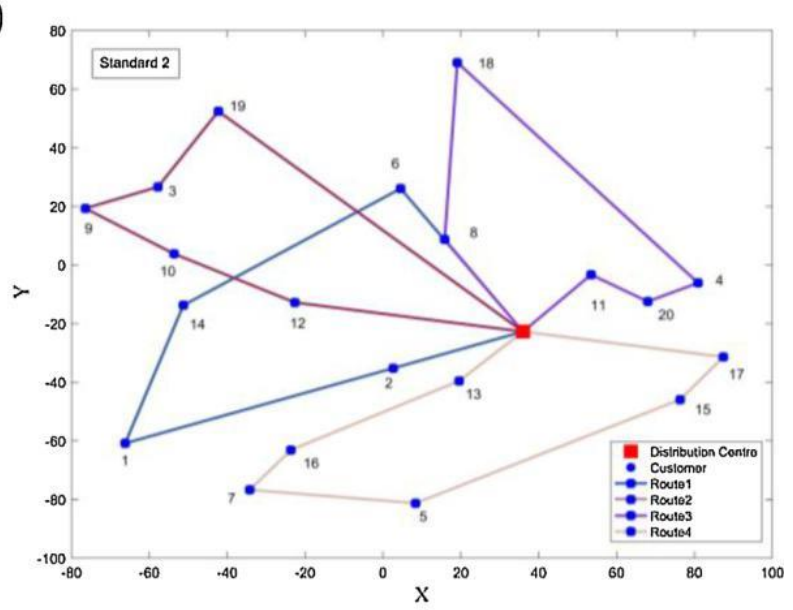

(d)

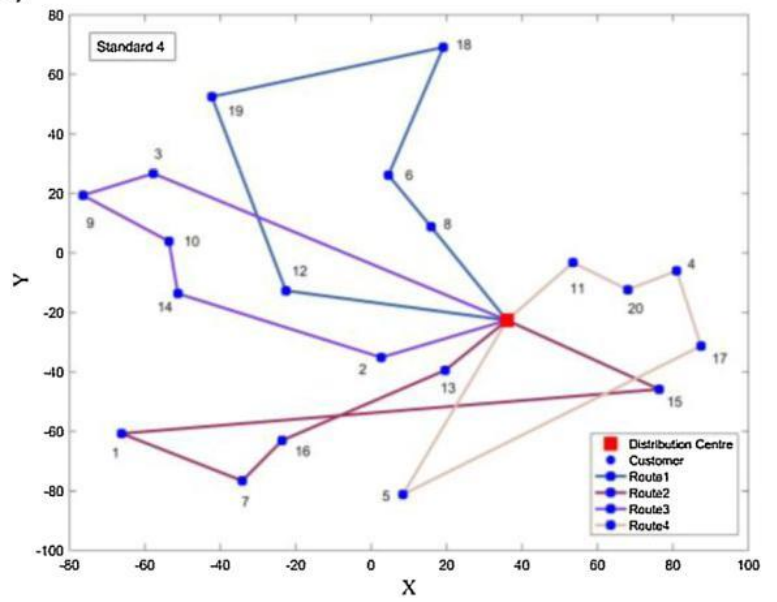

(f)

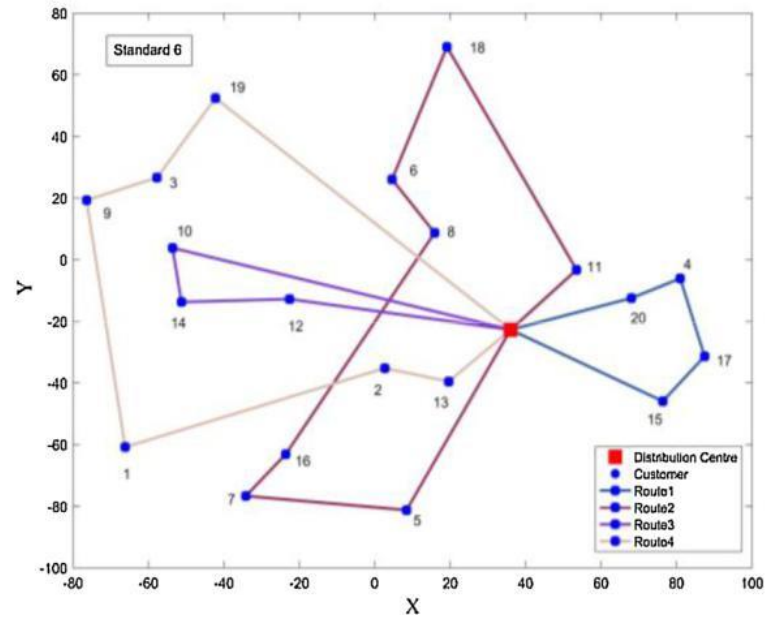

Fig. A2. Vehicle routes of CTS policy. 
(a)

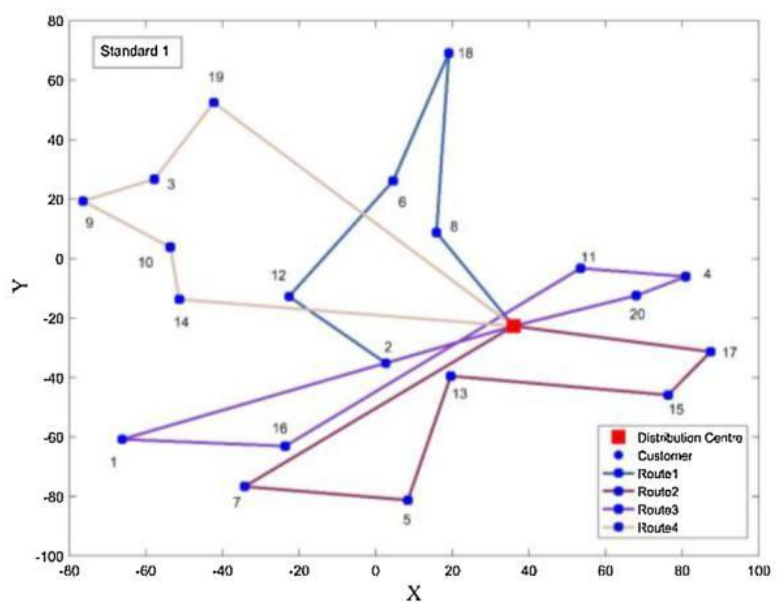

(c)

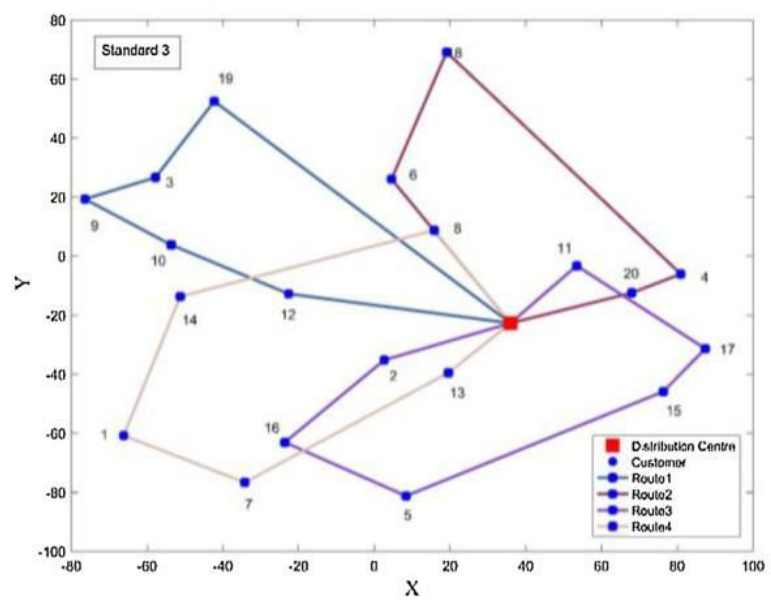

(e)

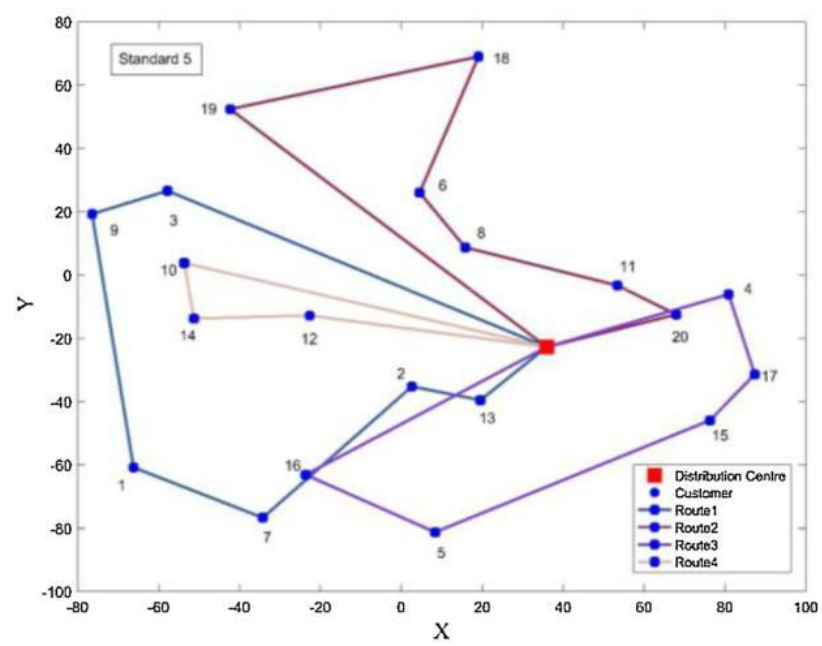

(b)

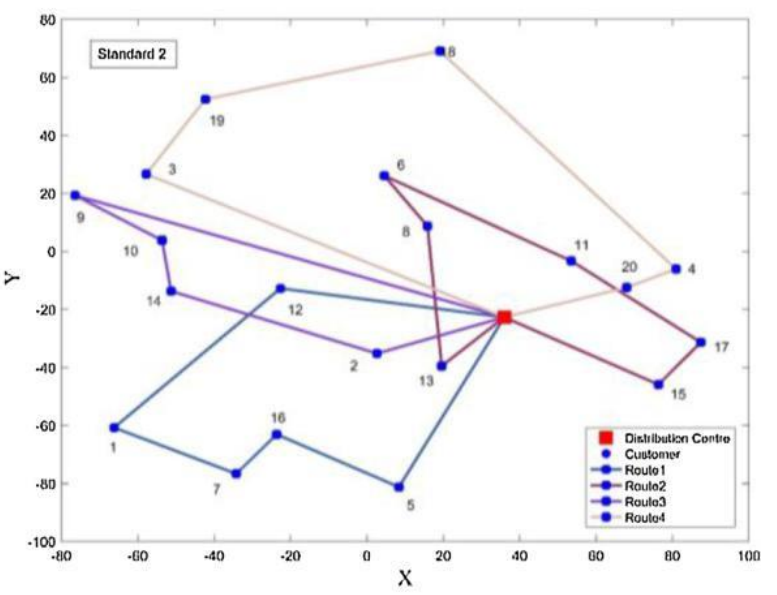

(d)

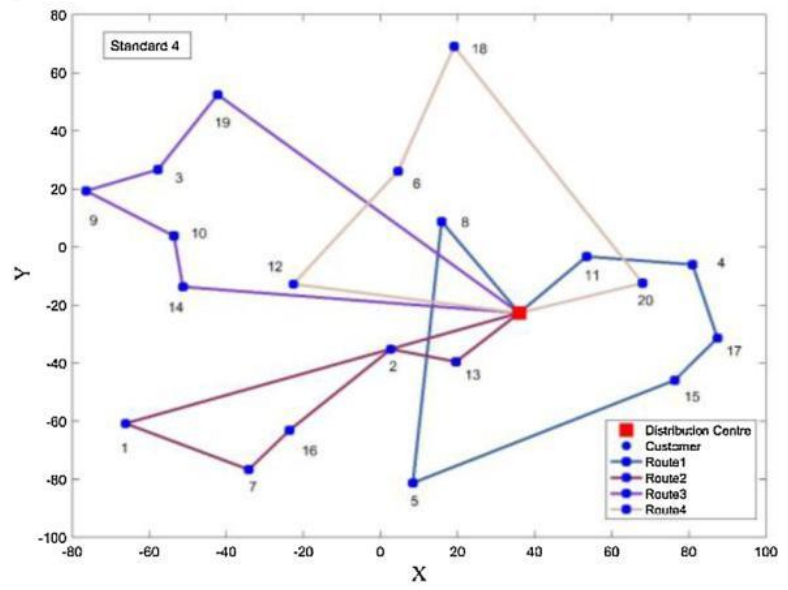

(f)

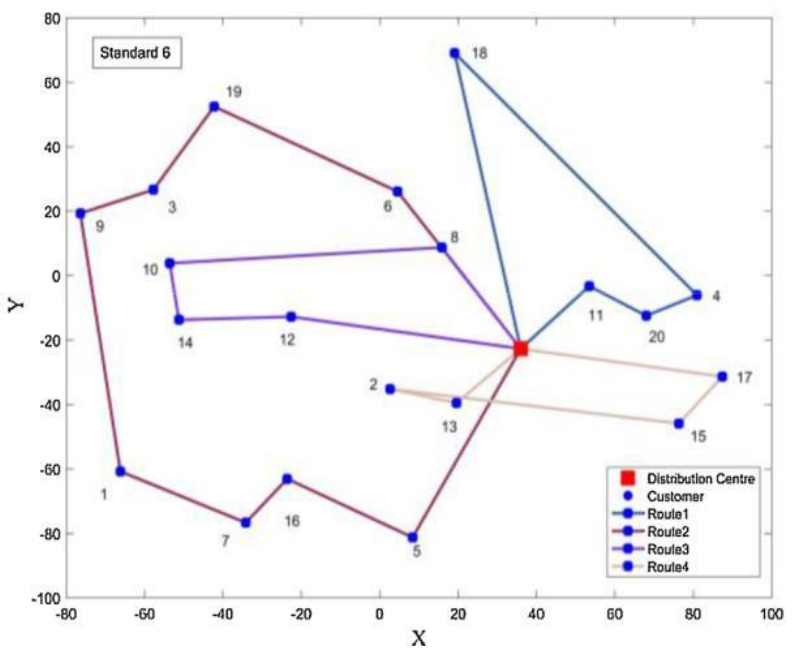

Fig. A3. Vehicle routes of $C Q$ policy. 
(a)

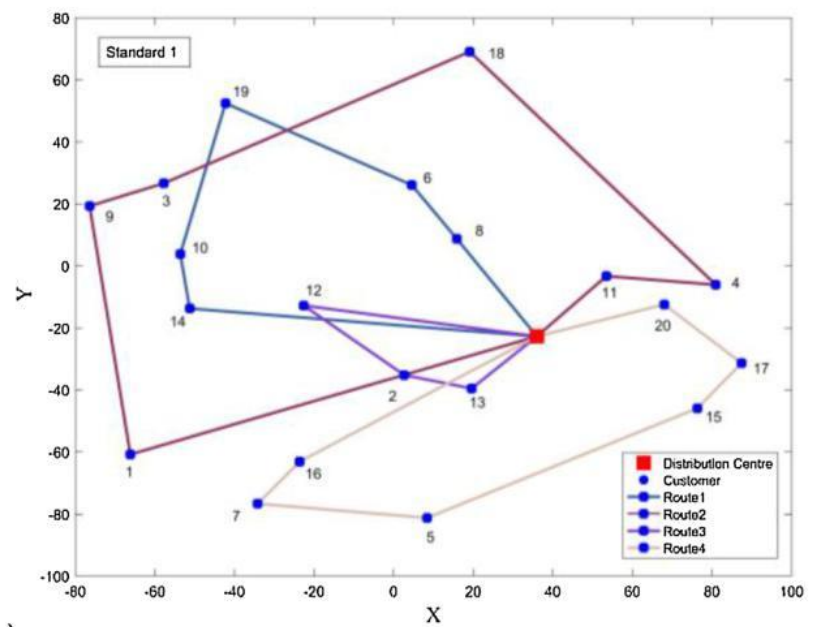

(c)

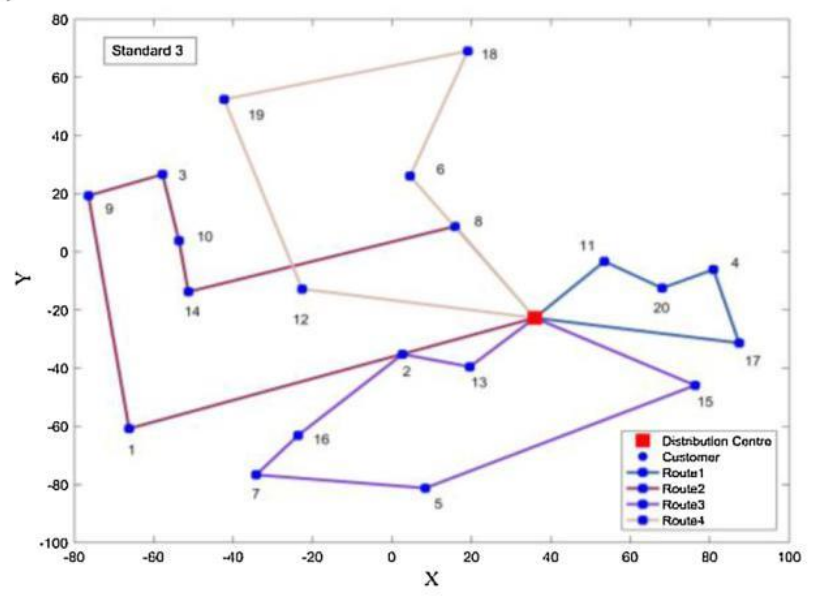

(e)

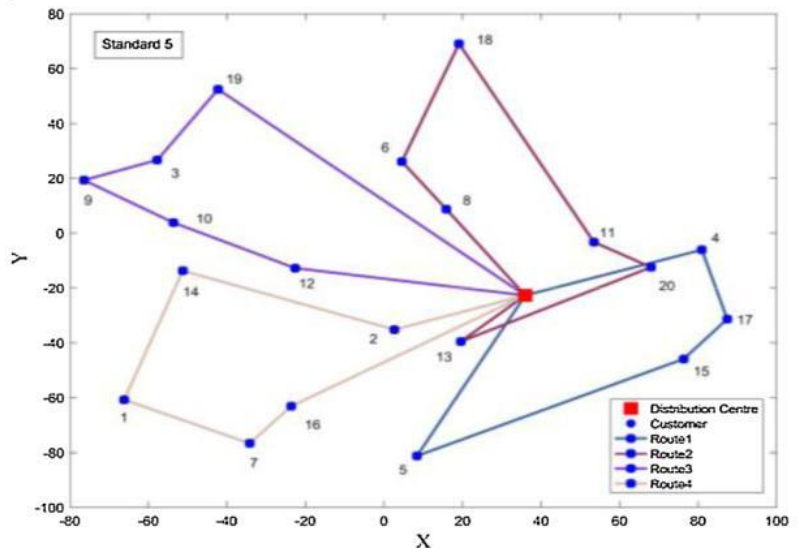

(b)

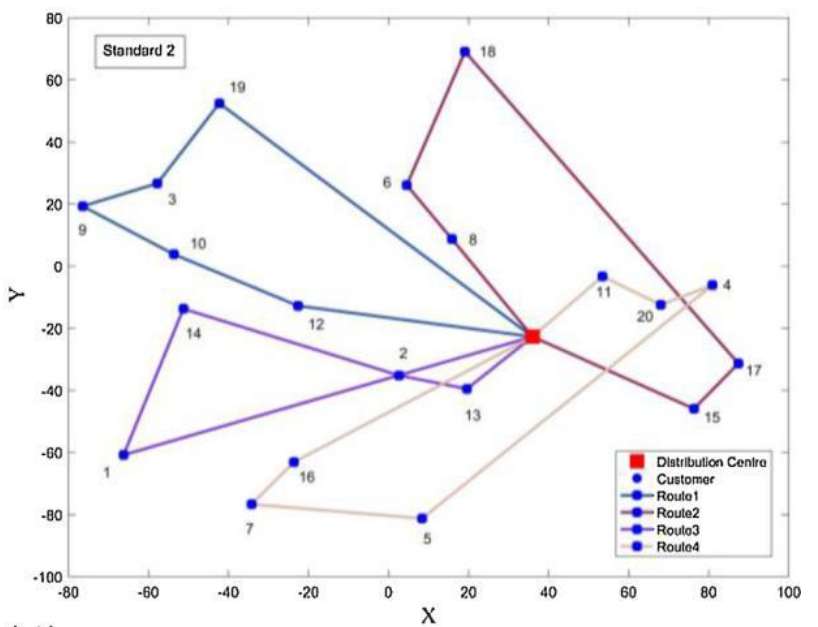

(d)

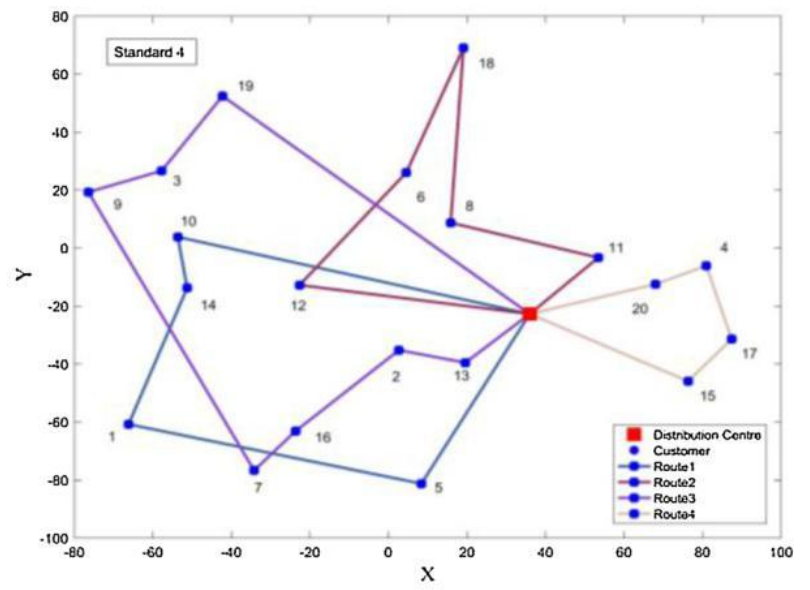

(f)

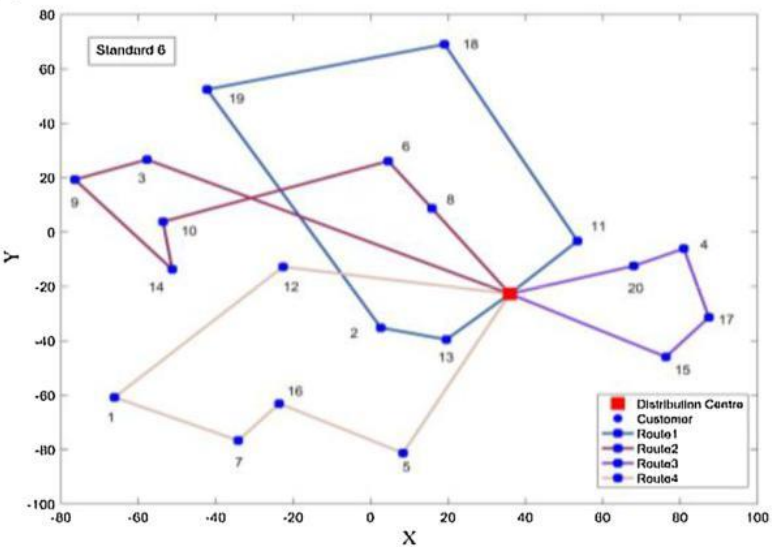

Fig. A4. Vehicle routes of CQS policy. 


\section{Appendix B}

See Fig. B1.

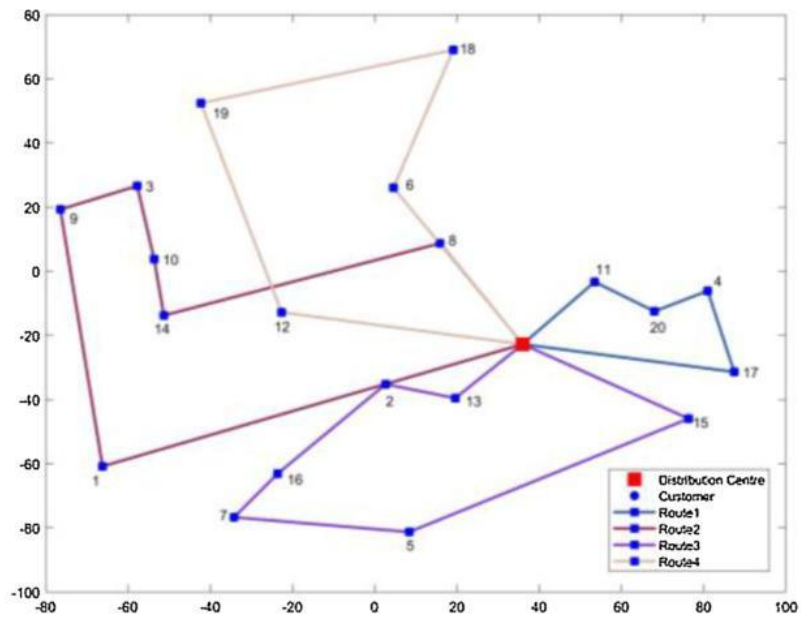

(a) $Q=3$

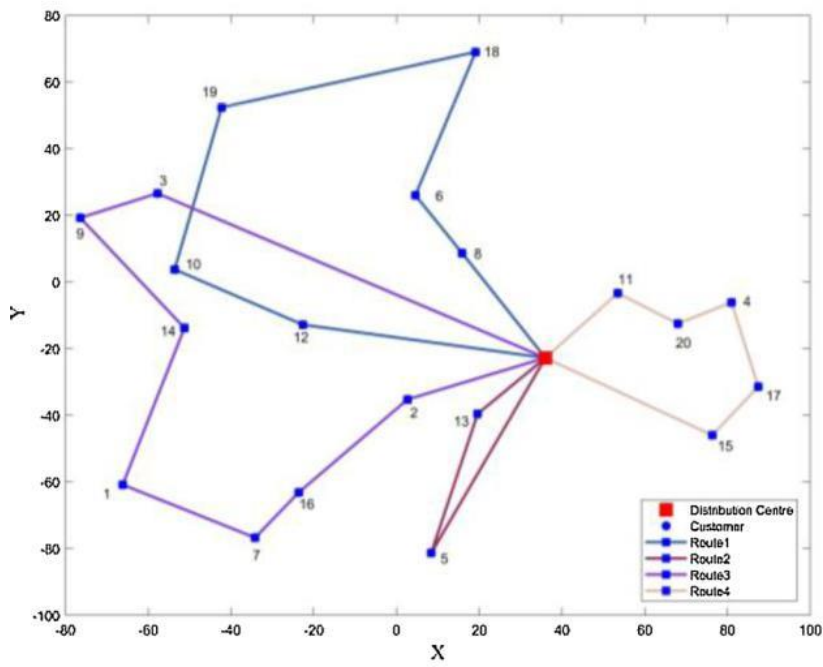

(b) $Q=4$

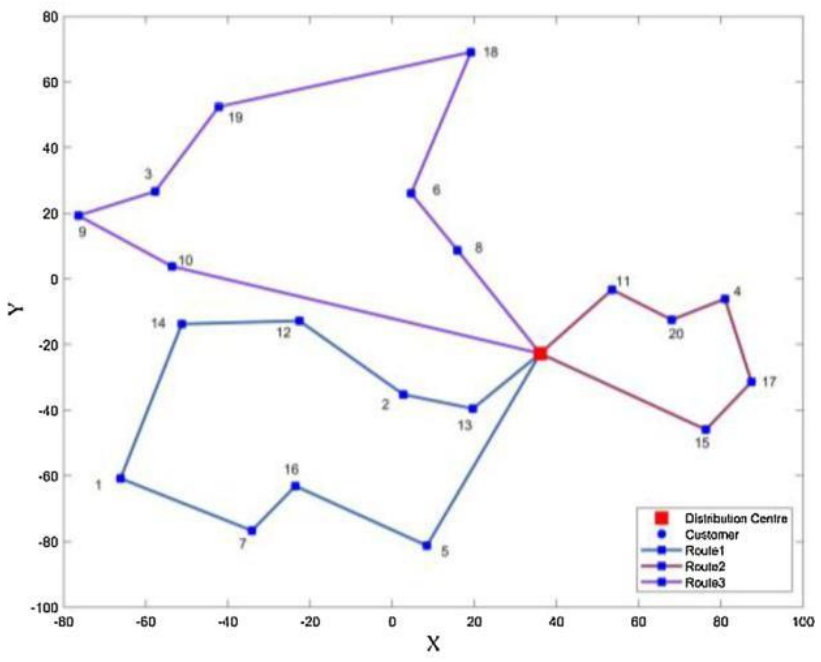

(c) $Q=5$

Fig. B1. Vehicle routes under different vehicle capacities.

\section{References}

Abedivaraki, M., 2017. Study of carbon dioxide gas treatment based on equations of ki-netics in plasma discharge reactor. Mod. Phys. Lett. B 31 (22), 1750210

Alberdi, R., Khandelwal, K., 2015. Comparison of robustness of metaheuristic algorithms for steel frame optimization. Eng. Struct. 102, 40-60.

Atasoy, B.S., 2017. Testing the environmental Kuznets curve hypothesis across the U.S.: evidence from panel mean group estimators. Renew. Sustain. Energy Rev. $77,731-747$.

Azadeh, A., Farahani, M.H., Eivazy, H., Nazari-Shirkouhi, S., Asadipour, G., 2013. A hybrid meta-heuristic algorithm for optimization of crew scheduling. Appl. Soft Comput. J. 13

(1), 158-164

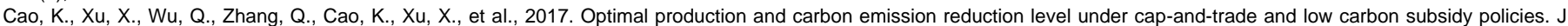
Clean. Prod. 167, 505-513.

Chen, J., Zhu, X., 2018. Optimization of multi-vehicle distribution vehicle routing under the carbon trading mechanism. Logist. Engi. Manage. 4, 105-109.

Chen, Z., Xu, L.P., 2015. A comparative analysis on the operating cost of freight en-terprises under implementation of carbon policies. Ind. Eng. J. 18 (3), 55-62.

Choi, K., Jang, D.H., Kang, S.I., Lee, J.H., Chung, T.K., Kim, H.S., 2016. Hybrid algorithm combing genetic algorithm with evolution strategy for antenna design. IEEE Trans. Magn. 52 (3), $1-4$

Dai, H., Masui, T., Matsuoka, Y., Fujimori, S., 2011. Assessment of china's climate com- mitment and non-fossil energy plan towards 2020 using hybrid aim/cge model. Energy Policy 39

(5), 2875-2887.

Desaulniers, G., Errico, F., Irnich, S., Schneider, M., 2016. Exact algorithms for electric vehicle-routing problems with time windows. Oper. Res. 64 (6), $1388-1405$.

Duan, F., He, X., 2014. Multiple depots incomplete open vehicle routing problem based on carbon tax. Commun. Comput. Informationence $472,98-107$.

Galinato, G.I., Yoder, J.K., 2010. An integrated tax-subsidy policy for carbon emission reduction. Resour. Energy Econ. 32 (3), $310-326$.

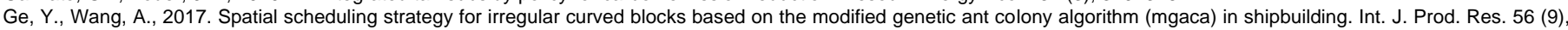
3099-3115.

Golden, B.L., Raghavan, S., Wasil, E.A., 2008. The Vehicle Routing Problem : Latest Advances and New Challenges. Springer, Boston, MA. https://doi.org/10.1007/978-0-38777778-8.

Goyal, N., Mittal, P., 2012. Comparative analysis of genetic algorithm, particle swarm optimization and ant colony optimization for tsp. Artif. Intell. Syst. Mach. Learn. 4, 202-206. He, Z., Chen, P., Liu, H., Guo, Z., 2017. Performance measurement system and strategies for developing low-carbon logistics: a case study in china. J. Clean. Prod. 156, 395-405.

Ji, S., Sun, Q., 2017. Low-carbon planning and design in b\&r logistics service: a case study of an e-commerce big data platform in china. Sustainability 9 (11), 2052.

Ji, S.F., Luo, R.J., 2017. A hybrid estimation of distribution algorithm for multi-objective multi-sourcing intermodal transportation network design problem considering carbon emissions. Sustainability $9(7), 1133$.

Jiang, P., 2015. Fault-tolerant multi-target localization based on k-means classification and tabu search in wireless sensor network. J. Inf. Comput. Sci. 12 (10), $3971-3982$.

Jiang, W., Liu, J., Liu, X., 2016. Impact of carbon quota allocation mechanism on emis-sions trading: an agent-based simulation. Sustainability 8 (8), 826.

Li, J., Lu, Q., Fu, P., 2015. Carbon footprint management of road freight transport under the carbon emission trading mechanism. Math. Probl. Eng. 2015 , 1-13 2015-9-7. 


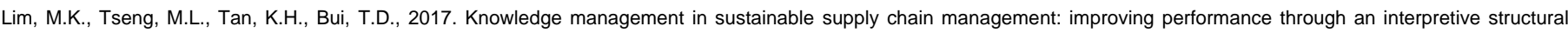
modelling approach. J. Clean. Prod. 162, 806-816.

Li, J., Zhang, J.H., 2014. Study on the effect of carbon emission trading mechanism on logistics distribution routing decisions. Syst. Eng. Theory Pract. 34 (7), $1779-1787$.

Liao, T.Y., 2017. On-line vehicle routing problems for carbon emissions reduction. Comput.-Aided Civil Infrastruct. Eng. 32 (12), 1047-1063.

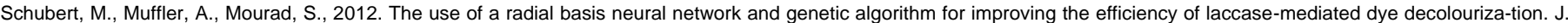
Biotechnol. 161 (4), 429-436.

Tamura, H., Teraoka, R., 2011. Assessing hybrid policy of carbon tax and emissions trading under uncertainty for preserving global environment. 18th World Congress of the International Federation of Automatic Control, Milano, Italy 28 August 2011.

Tang, S., Wang, W., Yan, H., Hao, G., 2015. Low carbon logistics: reducing shipment frequency to cut carbon emissions. Int. J. Prod. Econ. 164, 339-350.

Terefe, B.B., 2010. Greenhouse gas emissions from private vehicles in Canada, 1990 to 2007. Published May.

Thakur, P., Srivastava, D.C., Gupta, P.K., 2017. The genetic algorithm: a robust method for stress inversion. J. Struct. Geol. 94, 227-239.

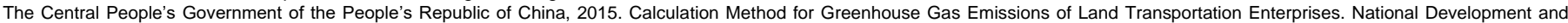
Reform Commission, People's Republic of China. http://www. ndrc.gov.cn/zcfb/zcfbtz/201511/t20151111_758275.html.

Walker, G., Manson, A., 2014. Telematics, urban freight logistics and low carbon road networks. J. Transp. Geogr. 37 (37), $74-81$.

Wang, C., Wang, W., Huang, R., 2017a. Supply chain enterprise operations and govern-ment carbon tax decisions considering carbon emissions. J. Clean. Prod. 152, 271-280.

Wang, S., Tao, F., Shi, Y., Wen, H., 2017b. Optimization of vehicle routing problem with time windows for cold chain logistics based on carbon tax. Sustainability 9 (5), 694 .

Xia, Y., Fu, Z., Tsai, S.B., Wang, J., 2018. A new TS algorithm for solving low-carbon logistics vehicle routing problem with split deliveries by backpack-from a green operation perspective. Int. J. Environ. Res. Public Health 15 (5), 949.

Xiao, Y., Konak, A., 2017. A genetic algorithm with exact dynamic programming for the green vehicle routing \& scheduling problem. J. Clean. Prod. 167, 1450-1463.

Yang, J., Guo, J., Ma, S., 2013. Low-carbon city logistics distribution network design with resource deployment. J. Clean. Prod. 119, $223-228$.

Yonhap News Agency, 2018. The EU plans to reduce carbon dioxide emissions by more than 30\% by 2030 . available at: http://www.mofcom.gov.cn/article/i/jyjl/j/ 201812/20181202819513.shtml (Accessed 30 August 2019).

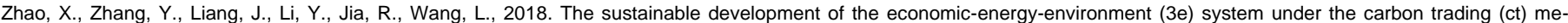
chanism: a Chinese case. Sustainability $10(1), 98$.

Zhang, J., Zhang, Y., 2018. Carbon tax, tourism co2, emissions and economic welfare

Ann. Tour. Res. 69, 18-30.

Zhang, J., Zhao, Y., Xue, W., Li, J., 2015. Vehicle routing problem with fuel consumption and carbon emission. Int. J. Prod. Econ. 170, 234-242.

Zhang, Mingyang, Haoran, 2017a. A study on the design of a hybrid policy for carbon abatement, China Population. Resour. Environ. (English) 15 (1), $50-57$.

Zhang, Z., Zhang, A., Wang, D., Li, A., Song, H., 2017b. How to improve the performance of carbon tax in china? J. Clean. Prod. 142, 2060-2072.

Zhou, L., Baldacci, R., Vigo, D., Wang, X., 2017. A multi-depot two-echelon vehicle routing problem with delivery options arising in the last mile distribution. Eur. J. Oper. Res. 265 (2), 765-778.

Zhou, Y., Hu, F., Zhou, Z., 2018. Pricing decisions and social welfare in a supply chain with multiple competing retailers and carbon tax policy. J. Clean. Prod. 190, 752-777. 